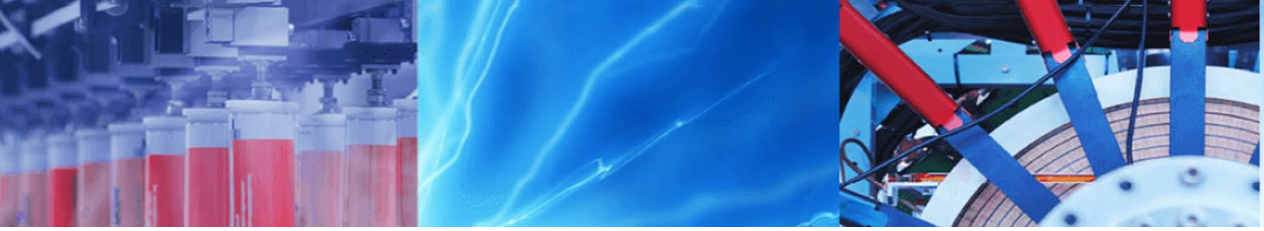

Case Study

\title{
Effect of blast loading and resulting progressive failure of a cable-stayed bridge
}

\author{
Ravi Mudragada' ${ }^{1}$ S. S. Mishra ${ }^{1}$
}

Received: 7 August 2020 / Accepted: 4 January 2021 / Published online: 15 February 2021

(C) The Author(s) 2021 OPEN

\begin{abstract}
Many researchers have carried out experimental and numerical investigations to examine building structures' response to explosive loads. Studies of bridges subjected to blast loads are limited. Hence, in this study, we present a case study on a cable-stayed bridge, namely, Charles River Cable-Stayed Bridge-Boston, to assess its robustness and resistance against the progressive collapse resulting from localized failure due to blast loads. Three different blast scenarios are considered to interpret the bridge performance to blast loads. To monitor the progressive failure mechanisms of the structural elements due to blast, pre-defined plastic hinges are assigned to the bridge deck. The results conclude that the bridge is too weak to sustain the blast loads near the tower location, and the progressive collapse is inevitable. Hence, to preserve this cable-stayed bridge from local and global failure, structural components should be more reinforced near the tower location. This case study helps the designer better understand the need for blast resistance design of cable-stayed bridges.
\end{abstract}

Keywords Cable-stayed bridge $\cdot$ Blast load $\cdot$ Localized failure $\cdot$ Progressive collapse $\cdot$ Plastic hinges

\section{Introduction}

A bridge during its service life may be subjected to possible blast loads either from accidental explosions or bombings. Since many bridges serve as transportation lifelines, are vital to the economy, and are usually the landmark structures of a region, their damage could have catastrophic consequences. Therefore it is crucial to protect bridge structures against blast loads. Explosive is widely used for demolition purposes in military applications, construction or development works, etc. [1] and has a great power to cause structural damage and injuries. The blast literature is mostly confined to RC and steel buildings, and indeed very little research has been done on the bridges [2]. David G. Winget, et al. [2] summarize the results of ongoing research to develop performance-based blast design standards explicitly tailored for bridges. Their study further discussed the potential effects of blast loads on bridges and provided structural design and retrofit solutions to counter these effects. The performance of three kinds of RC bridges, slab-on-girder bridge, a box-girder bridge, and a long-span cable-stayed bridge, under various blast loads, have been investigated by Yuxin Pan, et al. [3] and commented on the localized damage mechanism and the global structural response of all three bridges. William F. Cofer, et al. [4] created a finite element model of a precast, prestressed concrete girder bridge and validated them with two experimental blast tests. Three different scenarios were examined at the midspan of the bridge: a blast above and below the deck. The two load cases from above resulted in highly localized damage, with the possibility for other sections of the bridge to be immediately reopened after the event. Results for the load case from below indicated that the slab would be heavily damaged, but the girders will remain intact.

Ravi Mudragada, mudragadaravikumar1216@gmail.com; S. S. Mishra, ssmishra@nitp.ac.in | ${ }^{1}$ Civil Engineering, National Institute of Technology, Patna, Bihar 800005, India. 
Therefore, research on the bridges' blast analysis is gaining the most importance in the recent past. A few literature studies have been carried out on the cable-stayed bridges subjected to earthquakes, and their performances are evaluated [5-7]. Cable-stayed bridges are landmark structures involving huge costs, and their analysis and design to resist the extreme loads say the blast is of utmost importance. Tetougueni, C.D, et al. [8] studied the structural performance of a cable-stayed bridge under blast loading using an extensive numerical analysis. They have performed the nonlinear analysis on the generic cablestayed bridge to understand its ultimate capacity and later simulated the damage induced by the dynamic effect of a high impact action. Their result concluded the failure state of the bridge. JinSon and Ho-Jung Lee [9] investigated the performance of cable-stayed bridge pylons subjected to blast loading. In their study, the blast resistance of two different types of pylons was investigated. The study established damage patterns of the pylon and showed superior performance of the concrete-filled composite pylon over the hollow steel box pylon. To avoid the extensive computational time, P.J. Shukla and C.D. Modhera [10] have used a computer application SAP2000 and investigated a typical bridge model of cable-stayed bridge proposed for Surat city, Gujarat, India for blast load analysis. The calculated blast pressure as per TM-5-1300 [11] are converted into quasi-static blast loading and applied at different heights on a pylon. Comparative results for various heights of the explosion were obtained in multiple graphs for maximum bending moment, the shear force for different standoff distances. Simulations of a cable-stayed bridge subjecting to blast have been carried out numerically by Tang and Hao [12] to study the mechanism of damage and its intensity to the deck, piers, and towers. Dynamic response of cable-stayed bridge subjected to blast load was carried out by Hashemi et al.[13]; the results of the finite element simulations were used to evaluate the potential progressive collapse response of a cable-stayed bridge under various scenarios of blast loading. The role of redundancy in the bridge structural scheme was proved to be a strategic measure for avoiding disproportionate collapse, which occurs when an initial local failure produced by a small triggering event leads to the widespread failure of other structural components such that the whole structure collapses. It is also referred to as progressive collapse (Haberland et al. 2012; Starossek 2008; Starossek and Haberland 2010). Progressive collapse is a continuous spread of initial local failure from one member to another, finally causing the structure's collapse entirely or a disproportionately large part of it. In 2018, a portion of the highway connection viaduct over the Polcevera Valley in Genoa, Italy, collapsed. The reasons were identified as the sustained effects of fatigue and corrosion, lack of redundancy, construction abnormalities, etc. To observe the progressive collapse of a cable-stayed bridge numerically, M. Domaneschi [14] carried a post-collapse analysis of the Morandi's Polcevera viaduct by the applied element method (AEM). $M$. Domaneschi et al. [15] investigated the disproportionate collapse of an existing cable-stayed bridge, and an alternative configuration of the structural scheme was assessed as a possible countermeasure to improve the response of the cable-stayed bridge by providing different loading paths against disproportionate collapse. Gholamreza, G. et al. [16], performed a nonlinear numerical analysis to study the progressive damage assessment of cable-stayed bridge pier subjected to ship collisions.

Even though the robust and redundant behavior of cable-stayed bridges under various loading conditions offers good resistance against the progressive collapse, the need for further understanding of the behavior of cable-stayed bridges subjected to extreme loads is still a gap of study. Hence, Charles River Crossing Cable-Stayed Bridge-Boston [17] was considered as a case study and simulated in SAP2000 [18] to observe its response to blast loads. The author considered this case study only because of the available field data and nothing specific about the bridge and its characteristics. The purpose of this research work is to;

Give basic guidelines in analyzing the blast loads. Understand the response of Charles River Crossing Cable-Stayed Bridge-Boston to blast loads.

Study the robustness of considered cable-stayed bridge in resisting the progressive failure.

Investigate the post-yield behavior of the structural elements through the pre-defined plastic hinges.

Provide the concluding remarks on the considered bridge response and suggest the practical aspects of the performed study, which helps to the field of bridge engineering.

In this paper, a new method of analyzing the cablestayed bridges under blast loads is proposed. This study can be effectively used to supplement the finite element simulations and save both computational time and resources. At the end of this study, the potential reader can get a broad idea of information on the severity of blast loads on cable-stayed bridges and the importance of their design against progressive collapse. This study helps the designer better understand the robustness of cable-stayed bridges under blast loads and the importance of pylon and its characteristics in resisting the progressive collapse. This study contributes to the knowledge in the field of bridge engineering by concluding the volume of bridge design to high impact and explosive loads. 
Therefore, this paper is organized as follows. The paper's beginning presents the detailed methodology of the work to be followed, bridge information and specifications, material and geometric properties of the bridge, modal analysis of the Charles-River-Crossing CableStayed bridge-Boston, followed by blast information and their locations on the bridge deck. Later, a finite element model of the bridge developed using the commercial software SAP2000 to predict the bridge components' damage due to blast at all three locations on the bridge deck. The simulated results are used to assess the performance of the bridge components under the typical truck bombing loads. In the end, progressive collapse analysis of the bridge under dead loads is performed after damage to either one of the bridge components has occurred. Finally, the damage processes to the bridge components are observed, and damage mechanisms are discussed.

\section{Methodology}

The methodology adopted in this study has been explained clearly with a flow chart (Fig. 1).

Blast loads are very difficult to understand and analyze. Besides, the analysis of a cable-stayed bridge for blast load is even more complicated. Therefore, there is a need to simulate the blast load appropriately and then analyze its effect. In this study, to simplify the calculations and analysis, blast loads are converted into an equivalent static load and applied on the bridge elements as a uniformly distributed loads using the area tributary method [19]. In order to understand the critical blast locations on the bridge, three different blast locations have been chosen, and their effect on the structures has been analyzed. For every blast case, the chances of progressive failure have been estimated. A blast load of assumed magnitude is applied statically at three different locations, and the resulting deflections, forces, and stresses in the structural elements of the cable-stayed bridge are determined using SAP2000. Emphasis is also given in assessing the progressive collapse of a cable-stayed bridge that may result from localized failure. To simulate the cable-stayed bridge's progressive collapse under the blast loads, any structural element that exceeds its ultimate capacity is considered as an ineffective member (the second moment of inertia to be zero), and analysis is carried out further. On the other hand, to observe the bridge deck's post-yield behavior due to the blast, pre-defined plastic hinges are assigned to all bridge components. For every assigned hinge, the plastic force-deformation or moment-rotation curves are defined corresponding to the hinges with a specified degree of freedom as per FEMA-356 [20]. A typical generalized force-deformation curve is shown in Fig. 2, where line $A B$ represents linear elastic behavior. The slope from $A$ to $B$ represents the effective elastic stiffness of the member at yield. Point $B$ represents the expected yield strength of the member, and until this point, no deformation occurs in the plastic hinge. The line $B C$ represents strain hardening, and the slope from $B$ to $C$ is generally considered such that the ultimate capacity at point $C$ is $0-10 \%$ higher than
Fig. 1 Methodology of the work

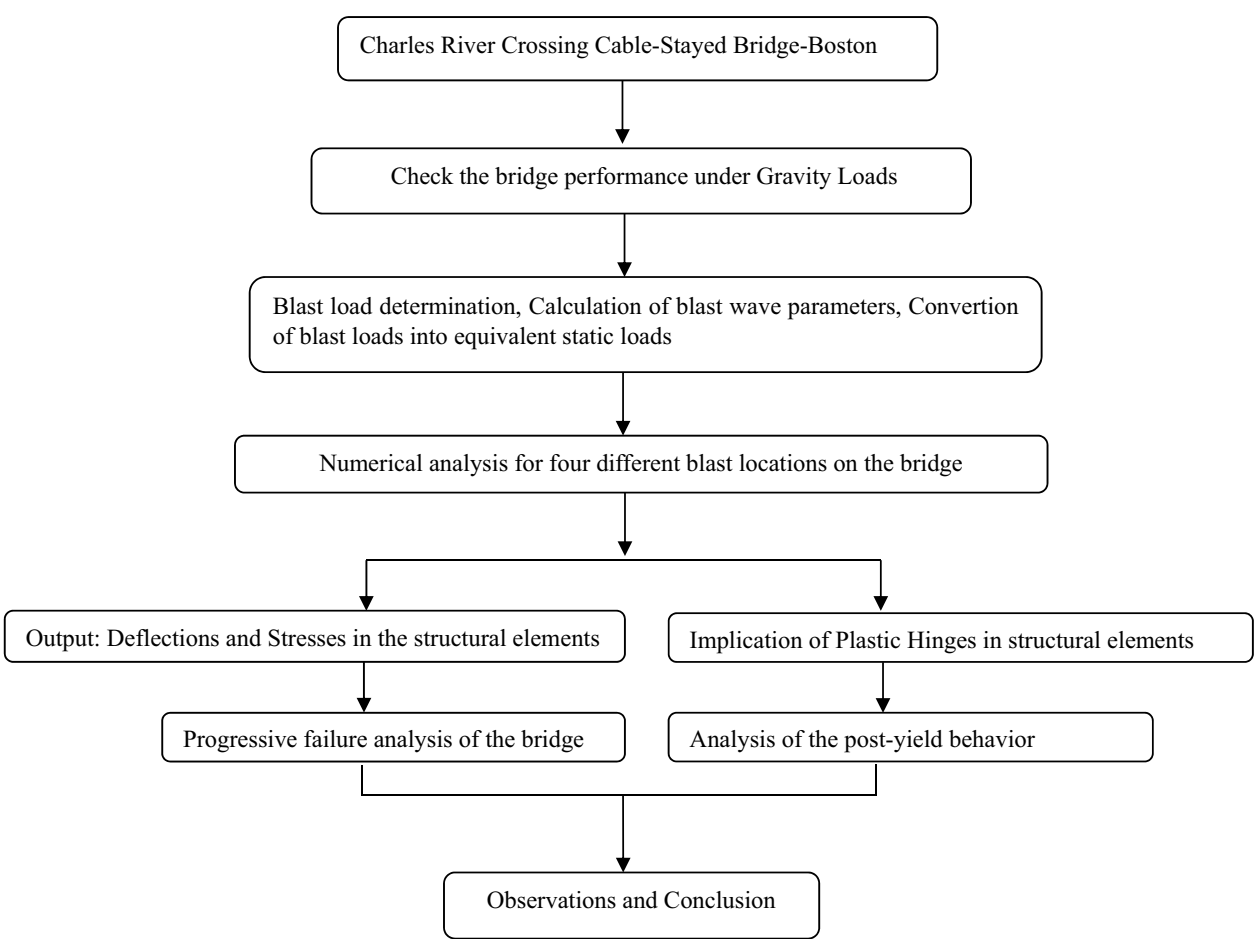




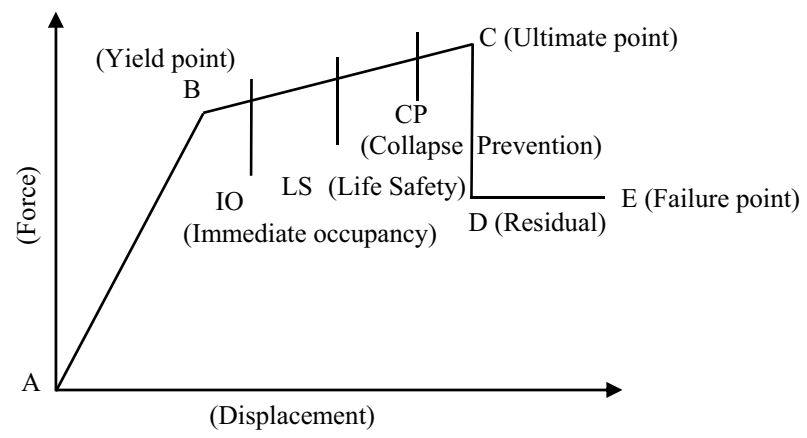

Fig. 2 Plastic force-displacement curve [ASCE 41-17]

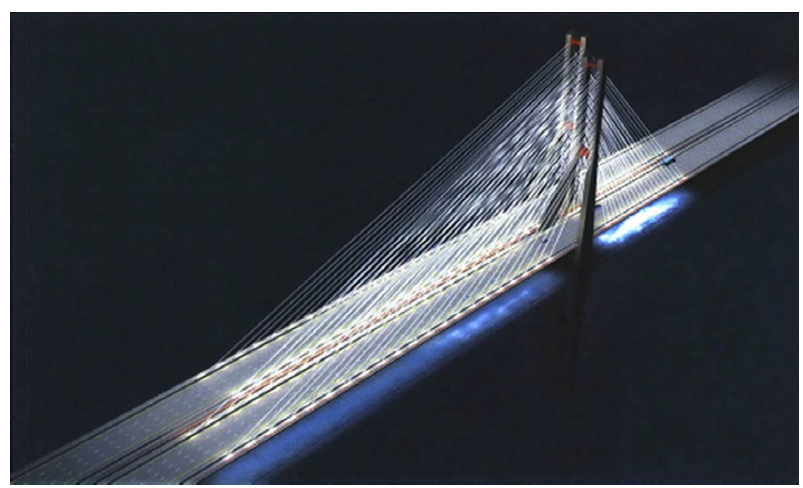

Fig. 3 Charles River Crossing Cable-Stayed Bridge [16]

the yield capacity. The line $C D$ represents the initial failure of the component. The line DE represents the member's residual strength, where point $E$ is considered a failure of the member. Figure 2 also shows the three performance levels of members, namely, Immediate Occupancy (IO), Life Safety (LS), and Collapse Prevention (CP). The acceptance criteria for plastic rotations corresponding to the three performance levels have been considered as per ASCE 41-17 (2017). After the nonlinear static analysis, if it is found that the hinge is in 10 (Immediate Occupancy), indicating limited damage, then the elements' original stiffness is maintained if not all of its strength. If the hinge is found to be in LS (Life Safety), then damage occurs in the element, and the element's stiffness is changed, but no severe damage in the element. If the hinge is in CP (Collapse Prevention), severe damage occurs in the element, and stiffness is completely changed.

\subsection{Bridge specifications}

The cable-stayed bridge shown in (Fig. 3) is a Charles River Crossing Cable-Stayed Bridge-Boston. It is a single tower cable-stayed bridge with the tower placed on one side. It

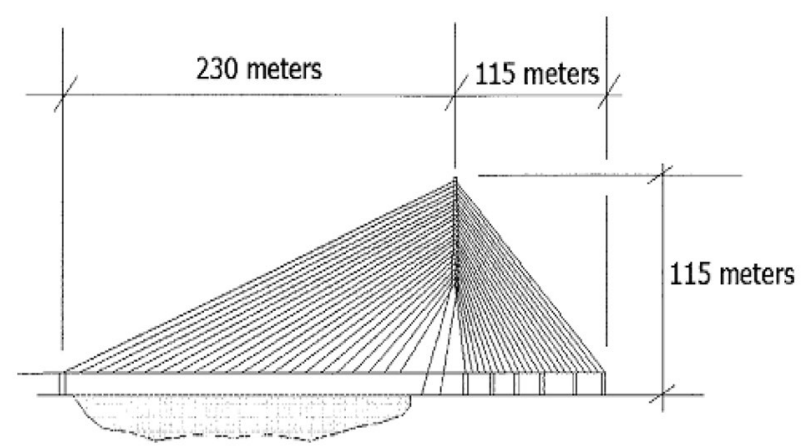

Fig. 4 Bridge dimensions-longitudinal

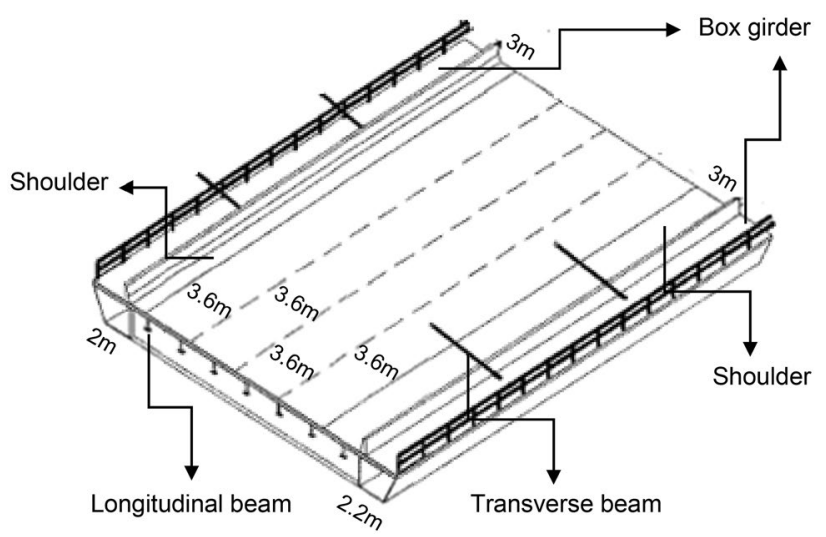

Fig. 5 Bridge deck dimensions-transverse

has a main span of $230 \mathrm{~m}$ and a back span of $115 \mathrm{~m}$ (Fig. 4), and the pylon rises $115 \mathrm{~m}$ above the ground surface.

The bridge's total width is $24.6 \mathrm{~m}$, and no of traffic lanes, shoulders, and pedestrian paths are shown in Fig. 5. The considered bridge has a single tower with a fan type of cable arrangement and a two-plane inclined transversal system. Backstay cables anchored to back span piers provide support for the tower (Fig. 4).

\subsection{Structural component details}

\subsubsection{Composite bridge deck}

The superstructure is configured to provide an effective and simple load path. The deck system is a $20 \mathrm{~cm}$ thick plate made of composite material. The deck is supported by longitudinal steel rolled I-beams that span $10 \mathrm{~m}$ between built-up steel floor beams. The steel floor beams are supported by closed steel box girders, which act as the main longitudinal members for the bridge (Fig. 6).

The composite deck material is a non-corrosive fiberreinforced polymer (FRP) composite deck. The deck section comprises hexagon and double trapezoid elements 
Fig. 6 Bridge deck

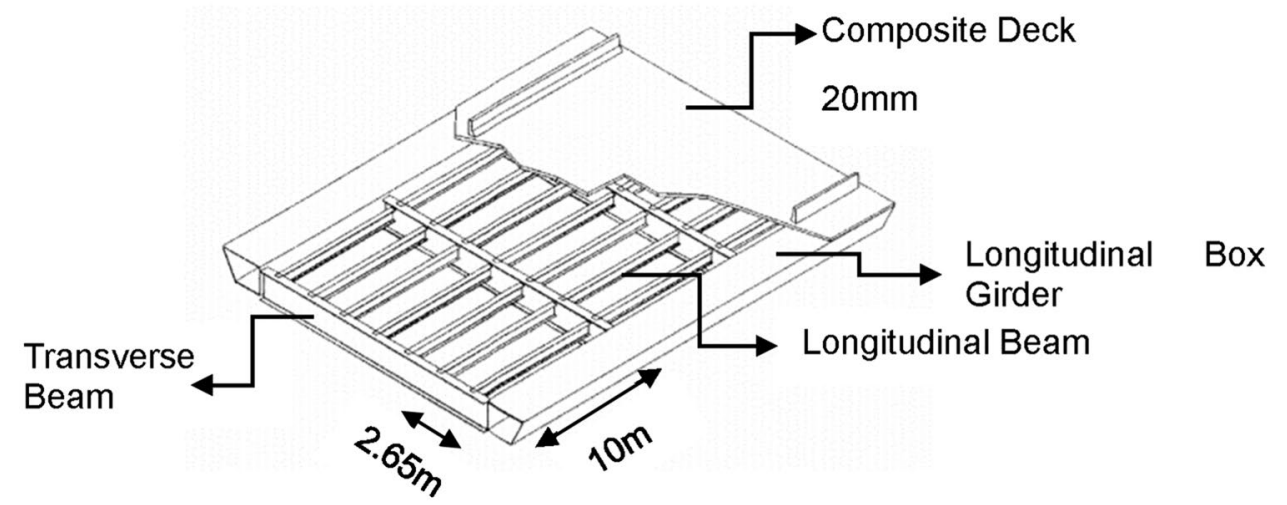

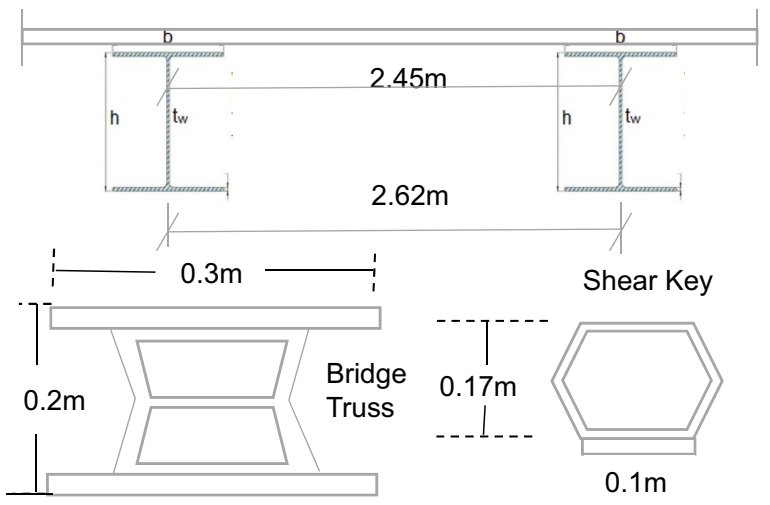

Cross Section along the length of bridge

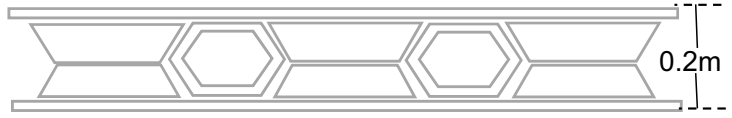

Fig. 7 Geometry of composite deck

Table 1 Deck properties

\begin{tabular}{lll}
\hline & Bridge truss properties & $\begin{array}{l}\text { Bridge shear } \\
\text { key proper- } \\
\text { ties }\end{array}$ \\
\hline Area $\left(\mathrm{m}^{2}\right)$ & $1.29 \mathrm{E}-02$ & $4.64 \mathrm{E}-03$ \\
$\mathrm{Ix}\left(\mathrm{m}^{4}\right)$ & $9.09 \mathrm{E}-05$ & $1.86 \mathrm{E}-05$ \\
$\mathrm{ly}\left(\mathrm{m}^{4}\right)$ & $7.32 \mathrm{E}-05$ & $1.86 \mathrm{E}-05$ \\
$\mathrm{Sx}\left(\mathrm{m}^{3}\right)$ & $8.95 \mathrm{E}-04$ & $2.09 \mathrm{E}-04$ \\
$\mathrm{Sy}\left(\mathrm{m}^{3}\right)$ & $4.83 \mathrm{E}-04$ & $1.84 \mathrm{E}-04$ \\
$\operatorname{Rx}(\mathrm{m})$ & $8.37 \mathrm{E}-02$ & $6.32 \mathrm{E}-02$ \\
$\operatorname{Ry}(\mathrm{m})$ & $7.52 \mathrm{E}-02$ & $6.32 \mathrm{E}-02$ \\
\hline
\end{tabular}

that are bonded together with a high-strength adhesive under controlled conditions in the manufacturing plant. This assemblage is installed transverse to the direction of traffic. It is connected to the longitudinal beam by a high-performance adhesive (Fig. 7) (Table 1).

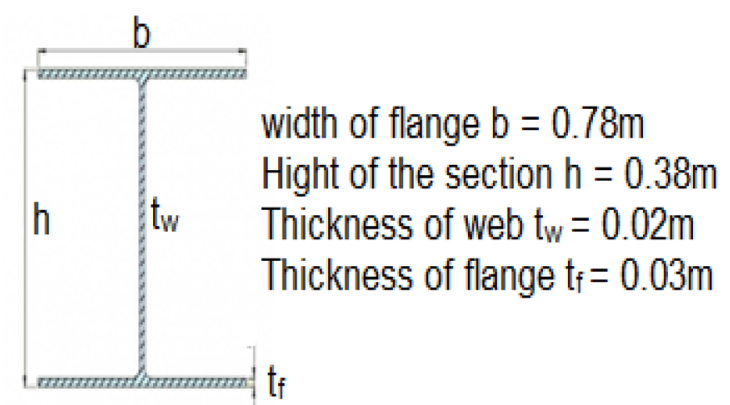

Fig. 8 Rolled steel section

Fig. 9 Box girder with tied cable

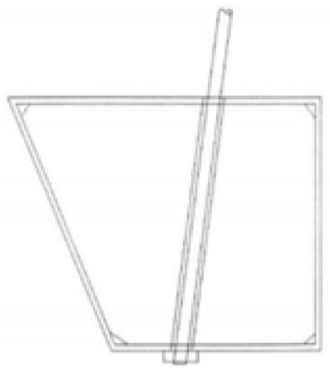

2.2.1.1 Longitudinal beams W30X191 rolled steel sections are used as longitudinal beams (Fig. 8). These beams are placed side by side with the spacing of 2.65 meters and used to support the composite deck. The span of each beam is $10 \mathrm{~m}$.

2.2.1.2 Longitudinal box girder These are built-up sections. Cables are tied to the box girders at every $10 \mathrm{~m}$ interval (Fig. 9). The box sections provide all the stiffness required by the deck. The structural system of the back span is the same as the main span. However, the back span should be more massive than the main span because it helps the tower resist the main span's forces and anchors the backstay cables. The steel box sections are filled with concrete to increase the weight of the back span. To provide a better connection between the steel and concrete, 
shear studs are placed on the bottom flange and on the web.

2.2.1.3 Transverse beams These are built-up sections with a top and bottom flanges having a dimension of $0.5 \mathrm{~m}$ by $0.05 \mathrm{~m}$. The web is having a size of $1.9 \mathrm{~m}$ by $0.05 \mathrm{~m}$. These beams are of span $18.3 \mathrm{~m}$ in length between longitudinal box girders and support the longitudinal beams.

2.2.1.4 Cables Seven wire high tensile strength strands of $15 \mathrm{~mm}$ diameter are used to make the cables (Fig. 10). These seven-wire strands are assembled in a hexagonal format. They are hot-dipped galvanized and are sheathed with a tight high-density polyethylene coating to prevent corrosion. The bundled mono strands are supplemented with an outer sheathing to reduce the cable anchorage connection's wind and rain effects. The cables have passive connections to the tower and an active connection to the longitudinal box girder.

2.2.1.5 Tower or pylon The tower has an inverted $\mathrm{Y}$ configuration, as shown in (Fig. 11), and it has a bent design for the first $60 \mathrm{~m}$ and a vertical structure above that distance (Fig. 12). The upper portion of the tower, where the cables are anchored, is reinforced with a steel plate. The tower has a box cross-section. The dimensions of the tower at the base is $10 \times 4 \times 0.5$ meters and tapers to $5 \times 3 \times 0.5$ meters where the bent section meets the straight portion. The straight part of the tower also has a box cross-section of dimension $5 \times 3 \times 0.5$ meters. Horizontal struts are placed in three locations along with the height of the tower. The tower is made of high-performance concrete with a 28-day compressive strength of 10,462 tons $/ \mathrm{m}^{2}$.

2.2.1.6 Summary of geometric properties The sectional and material properties of all the considered bridge's structural elements are shown below (Table 2).
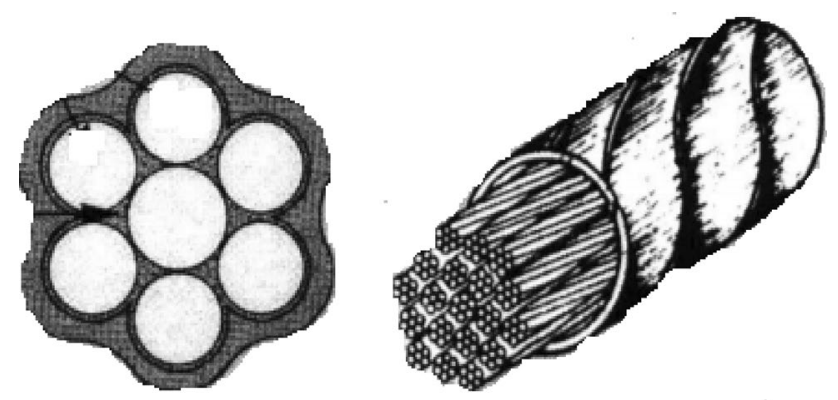

\section{Description of target bridge understudy}

The cable-stayed bridge shown in (Fig. 13) is a Charles River Crossing Cable-Stayed Bridge-Boston. The main and back-span lengths of the considered bridge are 230 and $115 \mathrm{~m}$, respectively. It is a single tower bridge with a tower height of $115 \mathrm{~m}$. The bridge has an inverted $y$-shape tower with a bent configuration for the first $60 \mathrm{~m}$ and a vertical configuration above this height. The height of the tower above and below the deck is 100.19 and $14.81 \mathrm{~m}$, respectively. A total of 88 cables are used in the cable-stayed bridge, and cables are equally distributed in both the main and back-spans (Table 3).

\subsection{Modal analysis}

Free vibration analysis was performed to understand the considered bridge's vibration characteristics, and

Fig. 11 Tower-front view

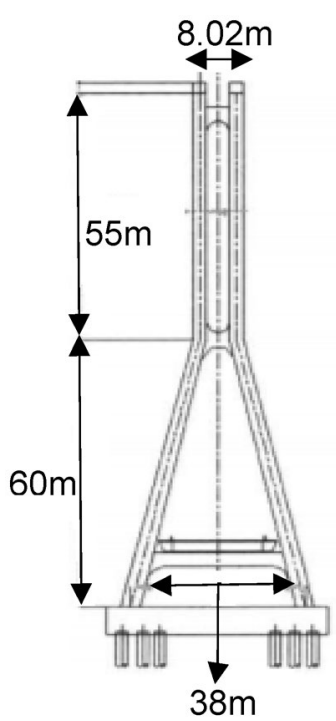

Fig. 12 Tower-side view

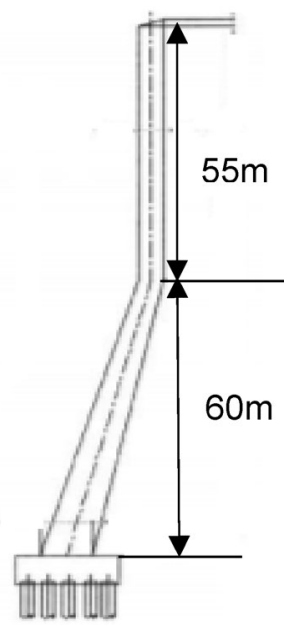

Fig. 10 Cable cross-section

SN Applied Sciences 
Table 2 Sectional and material properties

\begin{tabular}{|c|c|c|c|c|}
\hline & Box girder & $\begin{array}{l}\text { Longitudinal and trans- } \\
\text { verse girder }\end{array}$ & Top of the tower & Bottom of the tower \\
\hline Cross section area $\left(\mathrm{m}^{2}\right)$ & 0.76 & 0.145 & 7.00 & 13.00 \\
\hline Moment of inertia $\left(\mathrm{m}^{4}\right)$ & 0.45 & 0.0761 & 8.58 & 33.08 \\
\hline \multirow[t]{2}{*}{ Section modulus $\left(\mathrm{m}^{3}\right)$} & 0.45 & 0.0761 & 5.72 & 16.54 \\
\hline & Concrete & Steel & & Cables \\
\hline Density (tonf/m³) & 2.4 & 7.8 & Modulus of elasticity (tonf $/ \mathrm{m}^{2}$ ) & $2 \mathrm{E}+07$ \\
\hline Young's modulus (tonf $/ \mathrm{m}^{2}$ ) & $2.53 E+06$ & $2 \mathrm{E}+07$ & Ultimate stress (tonf $/ \mathrm{m}^{2}$ ) & $1860 E+02$ \\
\hline Poisson's ratio & 0.2 & 0.3 & Allowable stress (tonf/m²) & $1618 \mathrm{E}+02$ \\
\hline Grade(tonf $/ \mathrm{m}^{2}$ ) & 10,462 & 50,000 & & \\
\hline
\end{tabular}

Fig. 13 A 3-dimensional SAP2000 model of a cablestayed bridge

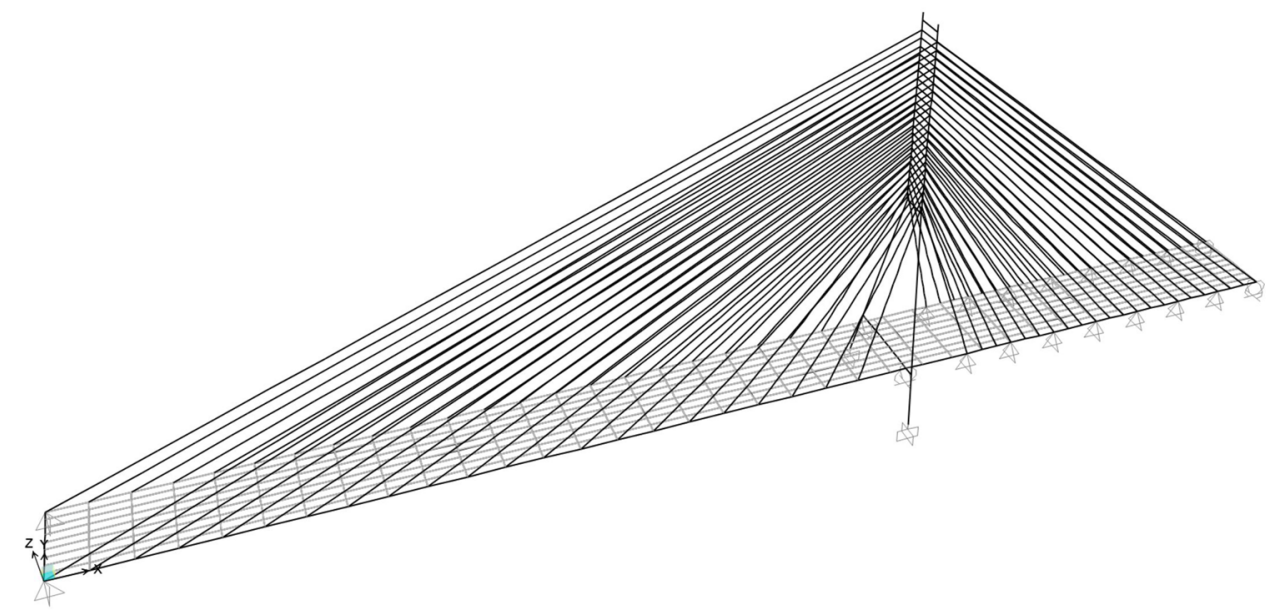

hence, different modes shapes and their characteristics were observed (Table 4). The bridge experienced a lateral bending of the deck as its fundamental mode shape with a fundamental time period of $5.48 \mathrm{~s}$ (Fig. 14). To check the accuracy of this modeling, the cable-stayed bridge's fundamental period was compared and validated with Davalos's (2000). The bridge was analyzed for 50 modes since the modal mass participation factor was more than $90 \%$ after 50 modes of the bridge, out of which the first ten modes are reported herein Table 4, and their mode shapes are shown clearly in (Fig. 14). The modal analysis concluded that the bridge lateral stiffness is lesser than its vertical rigidity.

\section{Calculation of blast loads on structures}

Blast loads are complex in nature. To simplify this complex loading and reduce the analysis time, a typical blast loading is converted into an equivalent static load using the TM 5-1300 Manual (1990). With the help of experimental results and scaling laws, charts are provided in the manual to calculate the blast load parameters for a given charge weight and standoff distance. The empirical formula to find the scaled distance, $\mathrm{Z}$ (ft), is mentioned in the Eq. (1). As per the TM 5-1300 (1990) manual, the amount of blast pressure generated is inversely proportional to the scaled distance.

$Z=\frac{R}{W^{\frac{1}{3}}}$

Here, $R=$ Standoff distance $(\mathrm{ft}), W=$ Equivalent TNT weight of explosion (lbs).

Using the scaled distance ' $Z$ ' and the charts in TM 5-1300, Applied Research Associates (ARA) [21] developed a computer program named ATBlast to calculate the blast loads for known values of charge weight and standoff distance. The ATBlast software [22] is widely used and recommended by the professionals to determine the equivalent blast pressure due to an explosion. Blue Ribbon Panel Report on Bridge and Tunnel Security (BRP 2003) [23] suggested that the highest possibility 
Table 3 Cable properties

\begin{tabular}{|c|c|c|c|c|}
\hline $\begin{array}{l}\text { Cable No (towards } \\
\text { the tower) }\end{array}$ & Area $\left(m^{2}\right)$ & Yield tension (tonf) & $\begin{array}{l}\text { Ultimate Tension } \\
\text { (tonf) }\end{array}$ & $\begin{array}{l}\text { Ultimate } \\
\text { Stress }=186,000 \\
\text { tonf } / \mathrm{m}^{2} \\
\text { Yield } \\
\text { stress }=161,820 \\
\text { tonf } / \mathrm{m}^{2}\end{array}$ \\
\hline 1 & 0.0206 & 3333.49 & 3831.6 & \\
\hline 2 & 0.0193 & 3123.126 & 3589.8 & \\
\hline 3 & 0.018 & 2912.76 & 3348 & \\
\hline 4 & 0.0168 & 2718.576 & 3124.8 & \\
\hline 5 & 0.0155 & 2508.21 & 2883 & \\
\hline 6 & 0.0143 & 2314.026 & 2659.8 & \\
\hline 7 & 0.0131 & 2119.842 & 2436.6 & \\
\hline 8 & 0.012 & 1941.84 & 2232 & \\
\hline 9 & 0.0109 & 1763.838 & 2027.4 & \\
\hline 10 & 0.0098 & 1585.836 & 1822.8 & \\
\hline 11 & 0.0088 & 1424.016 & 1636.8 & \\
\hline 12 & 0.0078 & 1262.196 & 1450.8 & \\
\hline 13 & 0.0069 & 1116.558 & 1283.4 & \\
\hline 14 & 0.006 & 970.92 & 1116 & \\
\hline 15 & 0.0051 & 825.282 & 948.6 & \\
\hline 16 & 0.0043 & 695.826 & 799.8 & \\
\hline 17 & 0.0036 & 582.552 & 669.6 & \\
\hline 18 & 0.003 & 485.46 & 558 & \\
\hline 19 & 0.0024 & 388.368 & 446.4 & \\
\hline 20 & 0.0022 & 356.004 & 409.2 & \\
\hline 21 & 0.0020 & 323.64 & 372 & \\
\hline 22 & 0.0019 & 307.458 & 353.4 & \\
\hline
\end{tabular}

Table 4 Bridge vibration characteristics

\begin{tabular}{lll}
\hline Mode number & Period (sec) & Modal characteristics \\
\hline 1 & 5.48 & Main span girder side bend \\
2 & 2.29 & Both main and back span girder side bend \\
3 & 1.93 & Main span girder vertical bend \\
4 & 1.62 & $\begin{array}{l}\text { Main span vertical and side bend, Tower side } \\
\text { bend }\end{array}$ \\
5 & 1.44 & Main span side and vertical bend, Tower side \\
& & bend \\
6 & 1.36 & Main span vertical bend \\
7 & 0.96 & Main span vertical bend and little side bend \\
& & also \\
8 & 0.55 & Main span vertical bend and Tower side bend \\
10 & 0.4 & Main span vertical and side bend \\
\hline
\end{tabular}

of a conventional truck bomb is an amount of $500 \mathrm{lbs}$ of trinitrotoluene (TNT) explosive. Hence, the ATBlast program is used to calculate the blast load parameters for a charge weight of 500lbs (Table 5).

\subsection{Blast load analysis}

A blast load of 500lbs is considered in the analysis. The minimum height above which the blast can happen is $4 \mathrm{ft}$ [24]. The effect of explosion diminishes as the scaled distance increases [25]. Hence, the maximum standoff distance of $25 \mathrm{ft}$ is considered in the analysis. Therefore, 
Fig. 14 Mode shapes
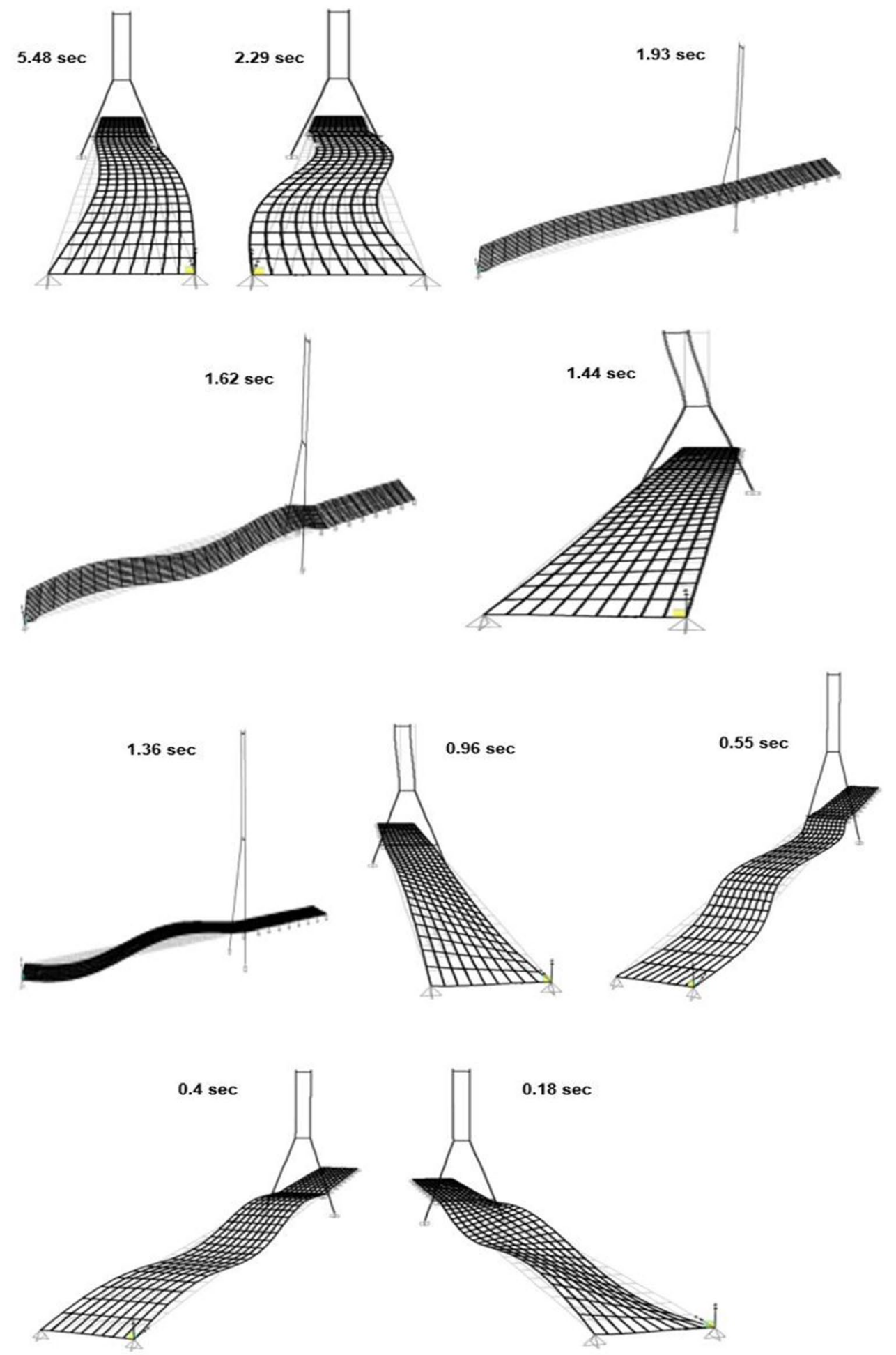

all the blast parameters are calculated for the scale distance of $4 \mathrm{ft}$ using the TM 5-1300 manual for a $500 \mathrm{lb}$ TNT charge weight. When a charge of $500 \mathrm{lb}$ weight is blasted at the height of $4 \mathrm{ft}$ on the center of a bridge, a maximum pressure of $2.511 \mathrm{ksi}$ is developed just below the blast location. The blast wave considered dispersing in all directions and effect all girders surrounded by the blast. Calculation of blast pressures on the deck's surface at every $1 \mathrm{ft}$ interval starting from the location of the explosion is shown in the below figure (Fig. 15). Using the area 
Table 5 Blast load parameters

\begin{tabular}{llllll}
\hline Charge weight, W(lbs) & Standoff, R (ft) & $\begin{array}{l}\text { Time of } \\
\text { arrival } \\
\text { (msec) }\end{array}$ & Pressure, P(psi) & $\begin{array}{l}\text { Impulse, } \\
\text { I(psi-msec) }\end{array}$ & $\begin{array}{l}\text { Pulse } \\
\text { duration } T_{d} \\
(\mathrm{msec})\end{array}$ \\
\hline 500 & 4 & 0.22 & 2511 & 326.68 & 0.26 \\
& 5 & 0.3 & 1884 & 235.17 & 0.249 \\
6 & 0.4 & 1480 & 190.72 & 0.257 \\
7 & 0.5 & 1198 & 167.111 & 0.278 \\
& 8 & 0.61 & 991 & 154.86 & 0.3125 \\
9 & 0.73 & 832 & 148.829 & 0.357 \\
& 10 & 0.87 & 707 & 146.93 & 0.42 \\
& 11 & 1.01 & 607 & 147.91 & 0.487 \\
\hline
\end{tabular}

Fig.15 Blast pressure distribution (Elevation)

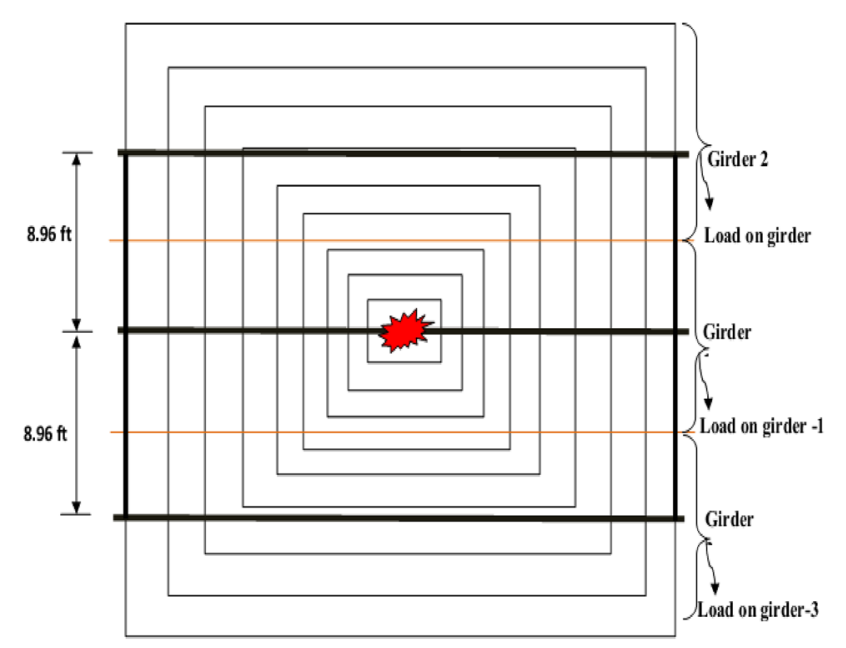

Fig. 16 Blast pressure distribution (Plan)

tributary method, average pressures on the surrounding girders are calculated (Fig. 16). Using the area tributary method, the uniformly distributed load on the girder- 1 is $877.36 \mathrm{klbs} / \mathrm{ft}$, and on both girder-2 and 3 is $198.6 \mathrm{klbs} / \mathrm{ft}$. Similarly, transfers girders loaded with 202.176 kips per feet. Such blasts are applied at three different locations on the bridge at the height of $4 \mathrm{ft}$ above the deck, and corresponding blast pressures on the surrounding elements are calculated. The three different blast locations on the bridge are shown below.

1. Starting of main span ( $220 \mathrm{~m}$ from tower location)

2. Middle of main span ( $120 \mathrm{~m}$ from tower location)

3. Near the tower (5 $\mathrm{m}$ from tower location)

\subsubsection{Starting of main span}

Bridge main span deck is loaded with the blast charge at the height of $4 \mathrm{ft}$ above the deck, as it is showing in Fig. The angle of dispersion of blast wave is assumed as $45^{\circ}$, and dispersion range of wave is limited to $10 \mathrm{~m}$ by $5.46 \mathrm{~m}$, and hence the loading is limited to the elements as shown in (Fig. 17).

The average pressure on the center girder (Element No-146) is $0.68 \mathrm{ksi}$ and on the two adjacent longitudinal girders is $0.153 \mathrm{ksi}$. Therefore using the area tributary method, the uniformly distributed load on the center 


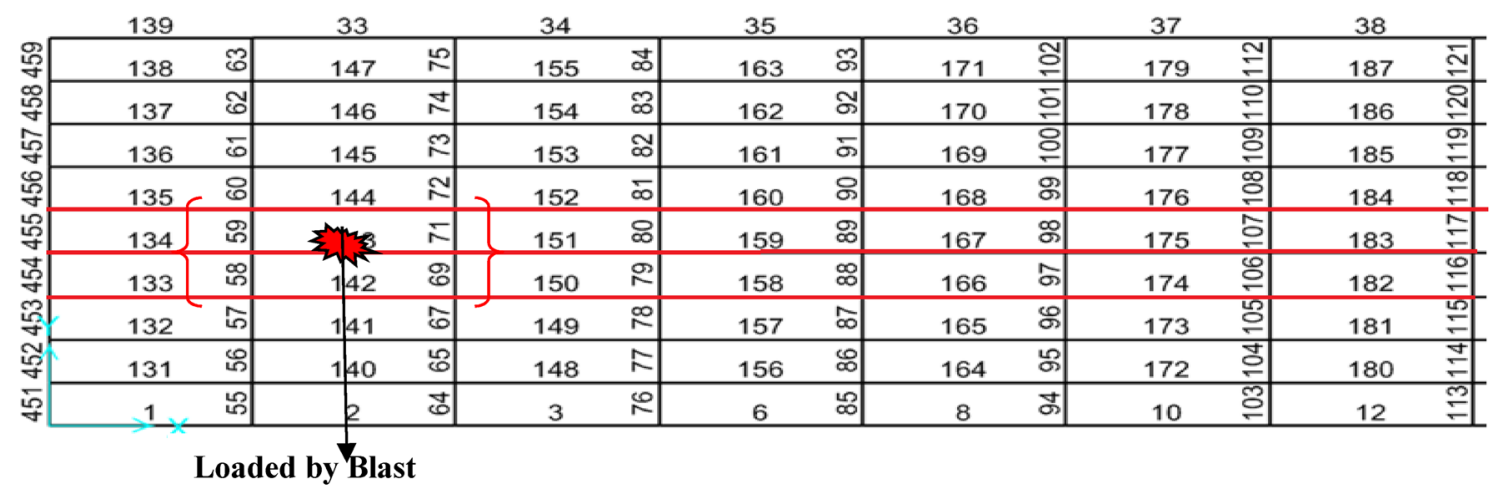

Fig. 17 Blasting location on the main span

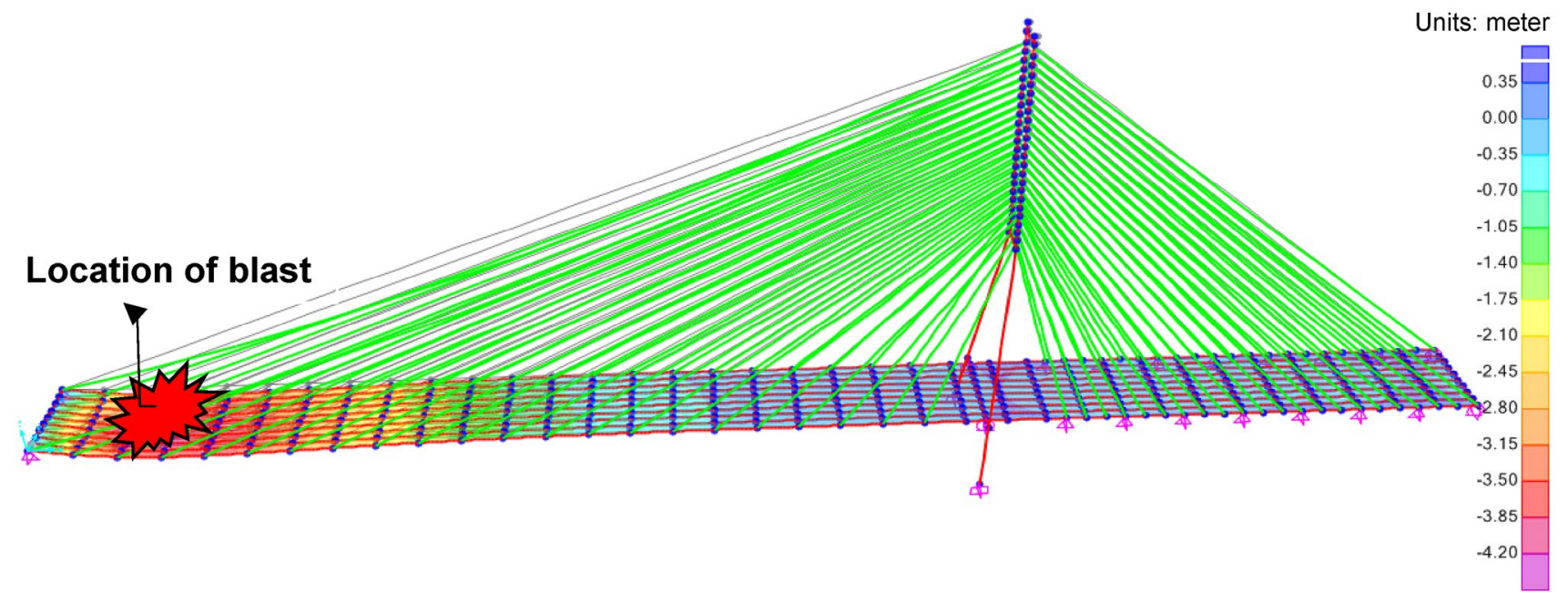

Fig. 18 Location of blast on the main span

longitudinal girder (Element No-143) is 877.36 kips per feet and on adjacent girders (Element No-144,142) 198.6 kips per feet. Similarly, transfer girders (Element No-58, 59, $69,71)$ are also loaded as a uniformly distributed load of 202.176 kips per feet. The bridge's deflection contours and joint displacement profile are shown in (Figs.18, 19).

Figure 19 shows that the bridge main span experienced a maximum displacement of $3.6 \mathrm{~m}$. Due to this large displacement of the main span, the cables attached to the box girders experienced many tensile forces. But, the tensile stresses in the main span cables were within their permissible limits, and hence no failure in the cables (Fig. 20). However, few of the girder elements (both longitudinal and transverse) near the blast location stressed more than their ultimate strengths and failed (Figs. 21, 22).

The progressive hinge formation in the frame elements for step loading is shown below (Fig. 23), which gives a clear idea about the hinges' status. So, therefore the mechanism of the structural members can be obtained, and countermeasure can be taken.

The localized failure that occurred on the bridge's main span may lead to the entire bridge's progressive collapse if it does not have robust and redundant behavior. Therefore to analyze the globalized failure, the damaged elements were removed from the bridge (shown as dashed lines), and analysis was carried out under the dead weight (Fig. 24). The analysis results concluded that localized failure of the bridge caused the progressive collapse by exceeding the maximum stresses in a few more girder elements around the blast location. Maximum stressed girder elements have been shown in the below table (Fig. 25). It was also found that no cable has failed during the analysis.

\subsubsection{Middle of main span}

Blast charge was placed in the middle of the main span, and loads were distributed to the girder element around 
Fig.19 Joint displacement in the main span towards the tower

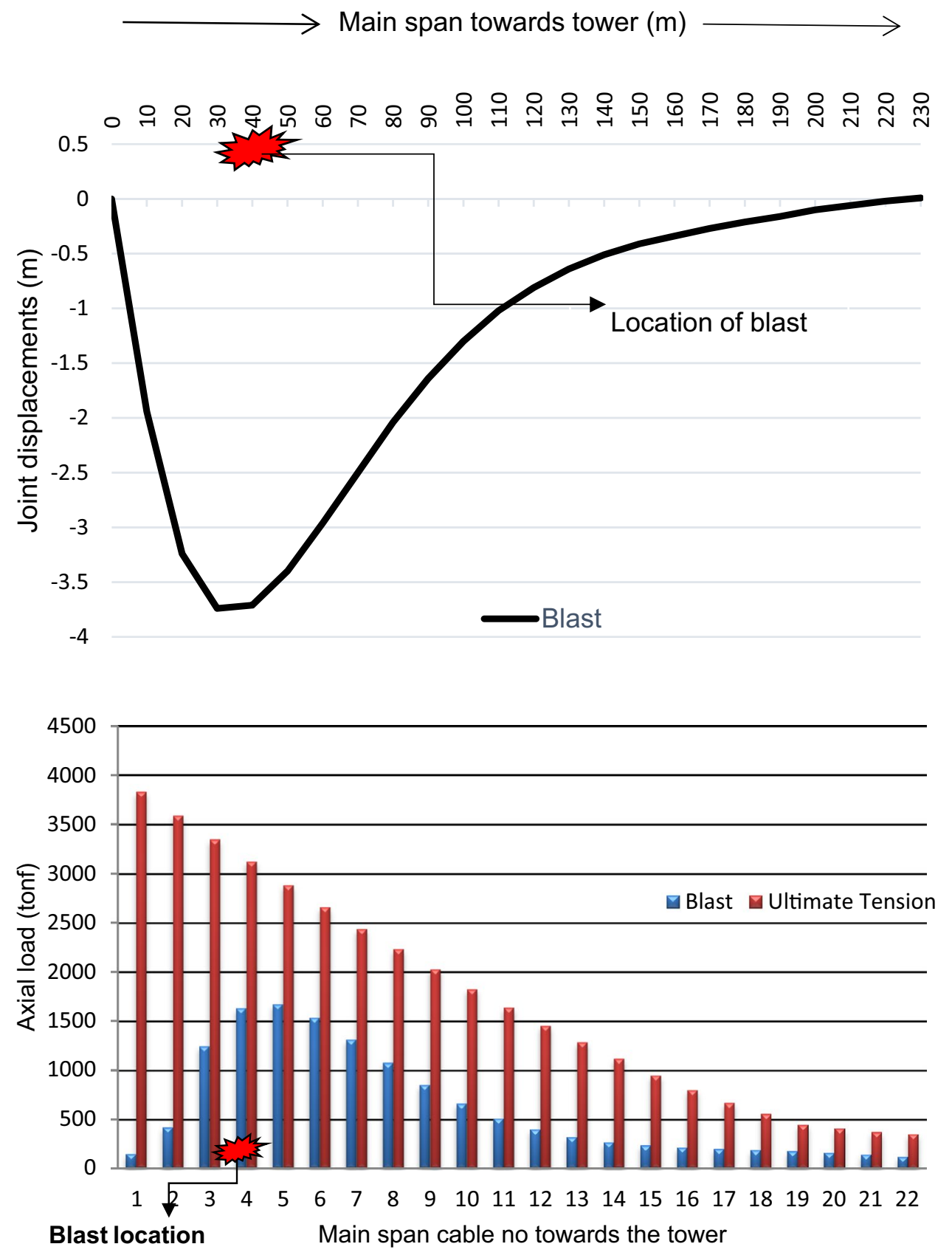

Fig. 20 Axial load in main span cables towards the tower the blast location following the same procedure as followed in Case-1. The girder element which are mainly affected by the blast loads are element no-214, 215, 216, $328,329,337,338$ (Fig. 26). The analysis was carried out using SAP2000, and the displacement contour profile of the bridge was observed under the blast loads (Fig. 27).

From Fig. 28, it is undeniable that the bridge experienced a maximum displacement of $7.2 \mathrm{~m}$ at the center of the main span, which indicated the severity of the blast at the middle of the main span. Due to the massive amount of stress in both transverse and longitudinal girders, the girder elements failed in flexure (Fig. 29). The stresses developed in the girders are transferred to the cables, and a large number of tensile forces are induced. From the results, it was clear that cables were affected more by the blast loads, and nine cables (Cable nos 9-17) exceeded their ultimate strength and failed (Fig. 30). The failed girder elements during the analysis are reported in (Fig. 31).

Therefore, the failure of cables and girder elements due to the blast loads at the center of the main span is called a localized collapse. Figure 32 shows the progressive hinge formation in the frame elements for step loading, which replicates the bridge components' progressive failure due to blast. This localized failure in 


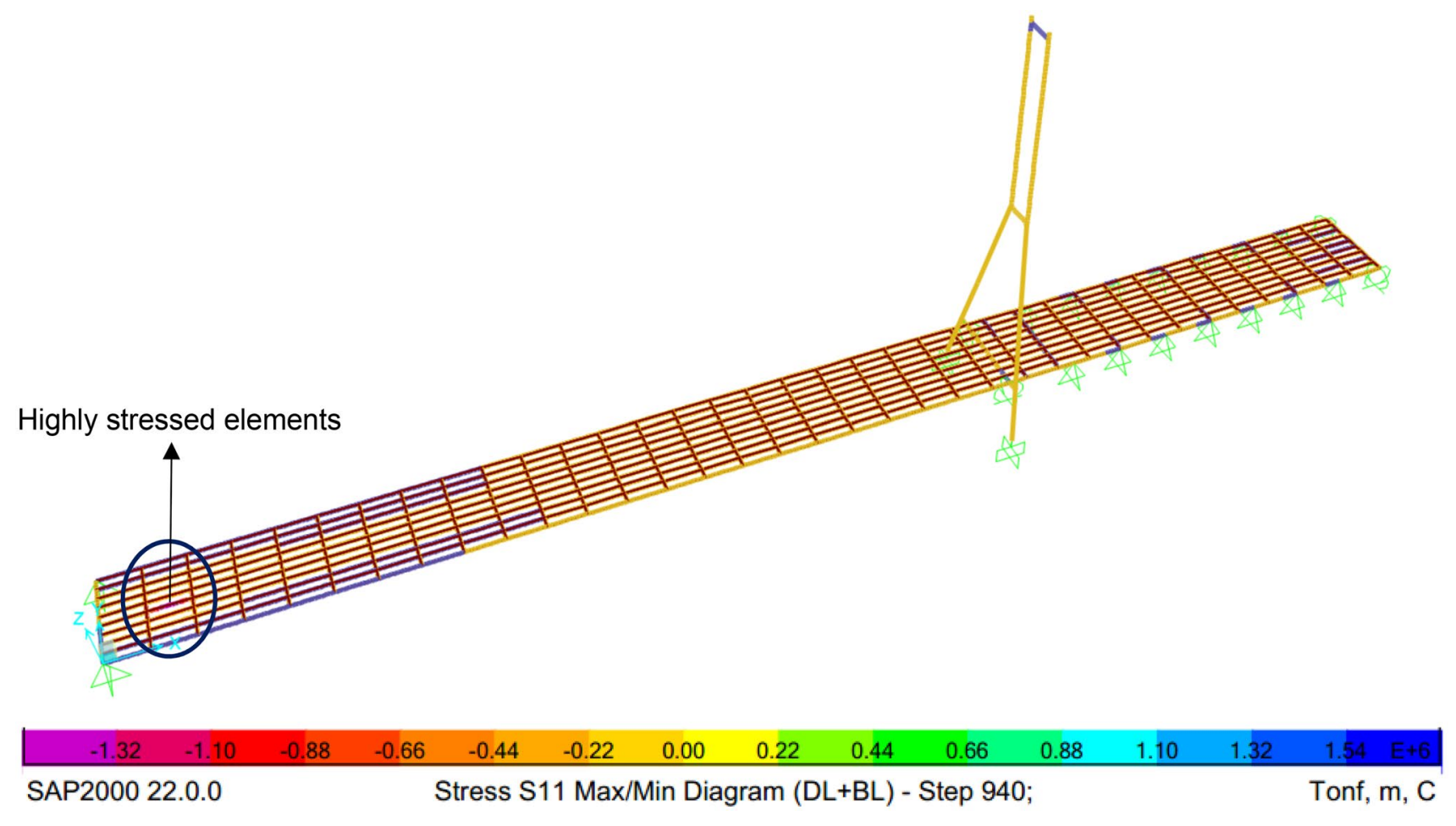

Fig. 21 Stress contours

Fig. 22 Stress demand vs. capacity of girder element

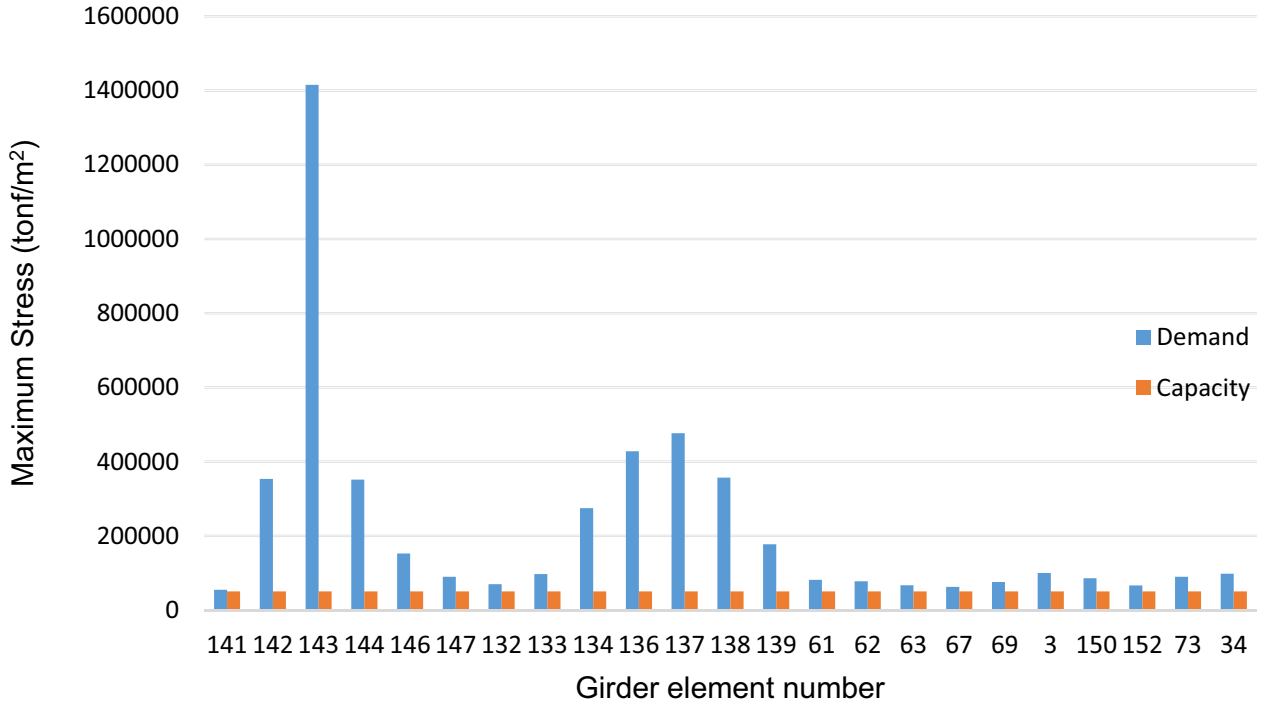

both cable and girder elements could lead to the entire bridge's progressive collapse.

Therefore to analyze the globalized failure, girders, and cables that exceed their ultimate strengths have been removed (shown as dashed lines) from the model, and analysis was carried out for the deadweight $[26,27]$.
Figure 33 shows the bridge SAP 2000 model after removing failed elements (both girders and cables).

It has been found that localized failure leads the bridge to a globalized failure by exceeding the maximum stresses in both girder and cable elements. Failed girders and cables during the post-blast analysis are reported (Figs. 34, 35) and (Table 6). 
Step 100

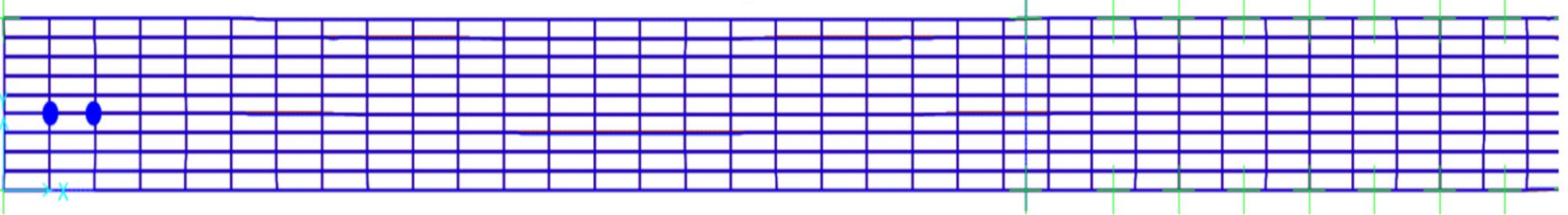

Step 250

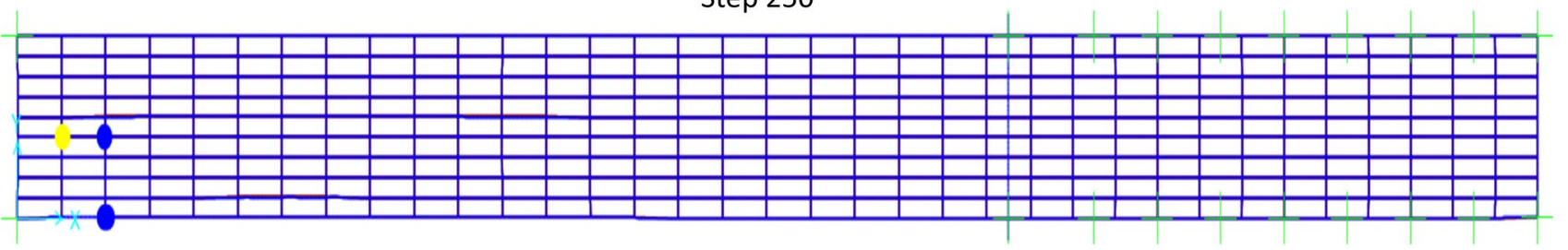

Step 300

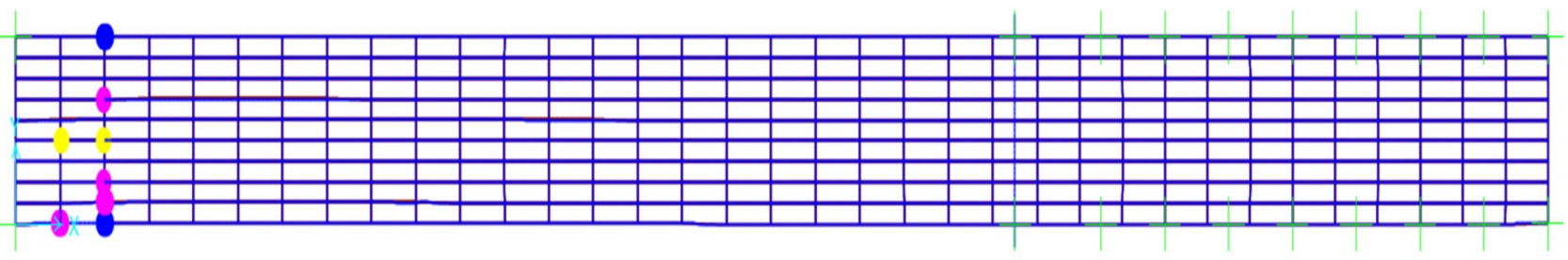

Step 500

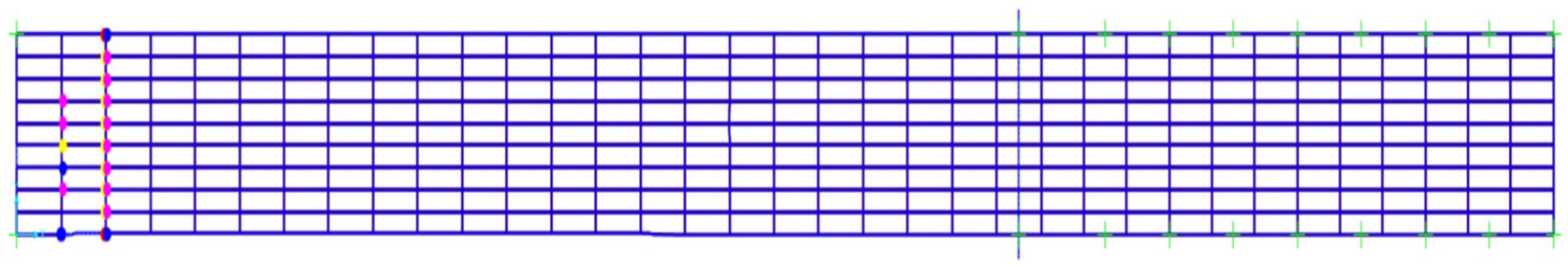

Step 940

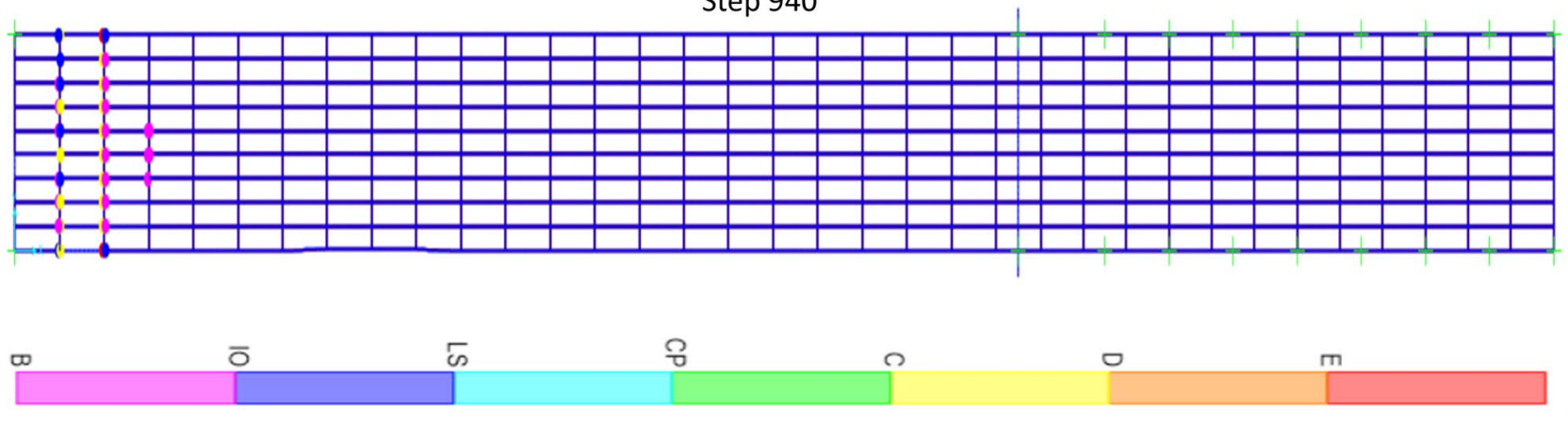

Fig. 23 Hinge formation due to blast load case-1

Therefore, it can be concluded that the effect due to blast loads on the considered cable-stayed bridge is more severe when the explosion occurred in the middle of the main span than case- 1 (explosion at starting of the main span).

\subsubsection{Near the tower location}

Following the same procedure as adopted in case- 1 and 2 , a blast charge was placed in the middle of the main span near the tower location and distributed the loads to 


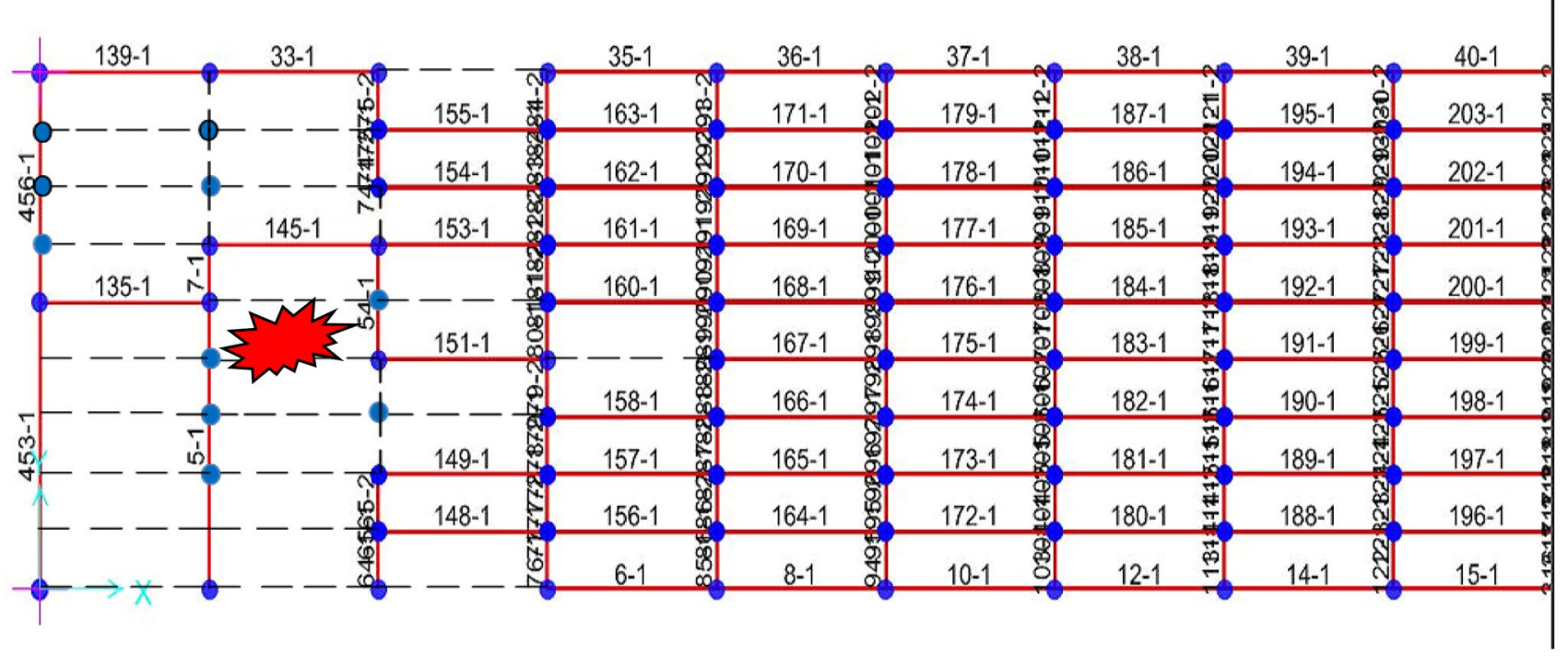

Fig. 24 Plan view of bridge deck after the localized collapse

Fig. 25 Stress demand vs. capacity of girder elementspost blast

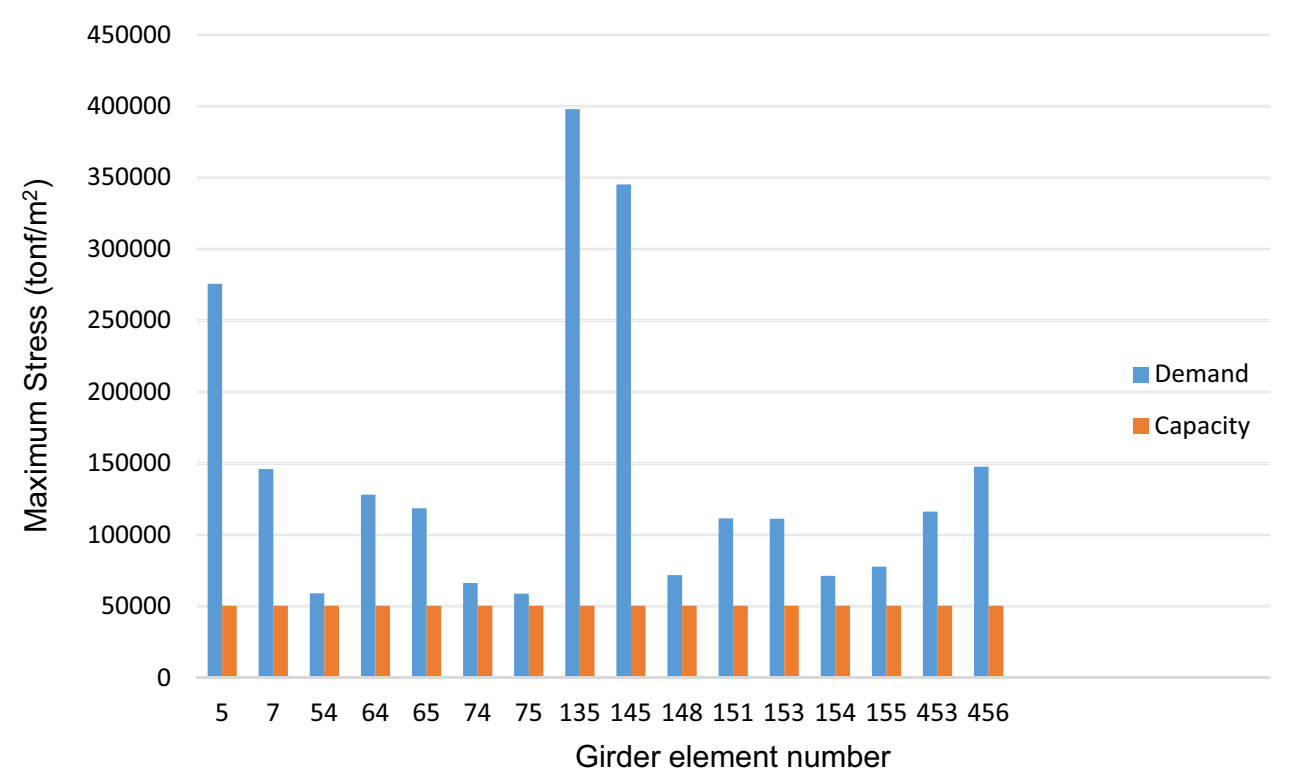

the girder elements around the blast location. The girder elements mainly affected by the blast loads are elements no-302, 303, 304, 427, 428, 436, 437 (Fig. 36). From the analysis, displacement contours and joint displacements of the bridge were recorded (Fig. 37). Bridge experienced a maximum displacement of $1.2 \mathrm{~m}$ at the center of the main span near the tower location (Fig. 38). From the result, it is evident that, when the blast occurs on the deck near the tower location, more number of cables (12) (Fig. 39) and girders (both longitudinal and transverse) were failed (Figs. 40, 41).
This localized failure leads to the progressive collapse of the structure. Results from the post-blast analysis of the damaged bridge show that a few girder elements and cables failed and caused the bridge's severe globalized collapse. Hence, it is concluded that damage due to blast near the tower location is more severe than any other place.

Figure 42 shows the progressive hinge formation in the frame elements for step loading, which replicates the bridge components' progressive failure due to blast.

To observe the progressive collapse resistance, the bridge was analyzed for dead loads after removing the bridge model's failed elements (Fig. 43). Therefore, it was noticed that 


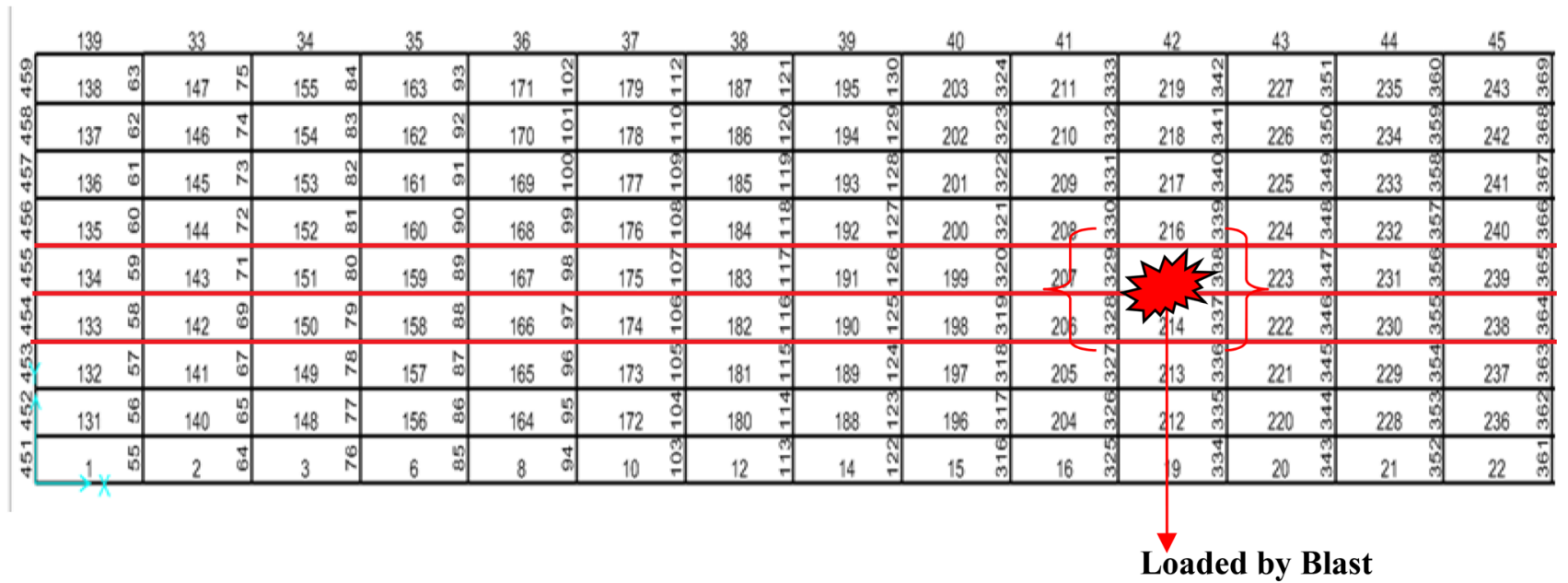

Fig. 26 Blasting location on the main span

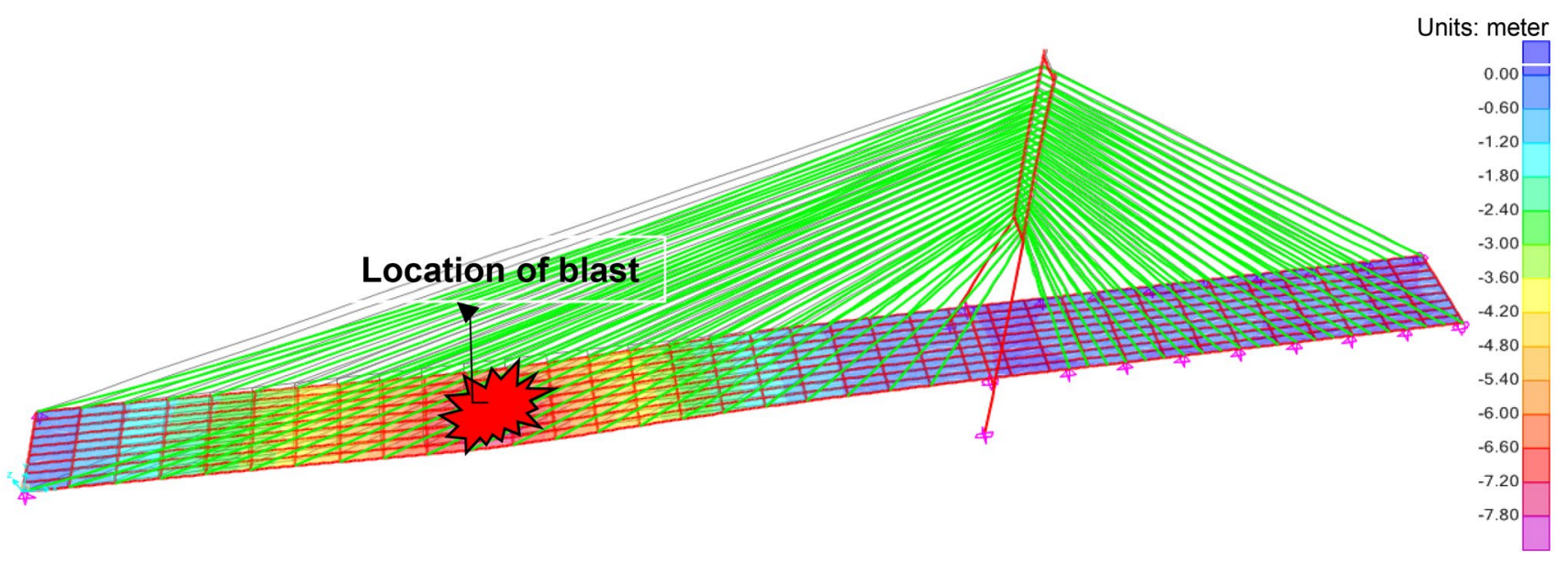

Fig. 27 Displacement contour

Fig. 28 Joint displacement in the main span towards the tower
$0 \quad 1020 \quad 30 \quad 4050 \quad 60 \quad 70 \quad 80 \quad 90100110120130140150160170180190200210220230$

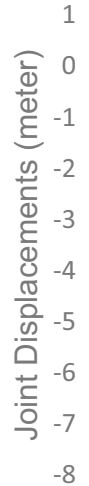

Main span towards tower

Blast 


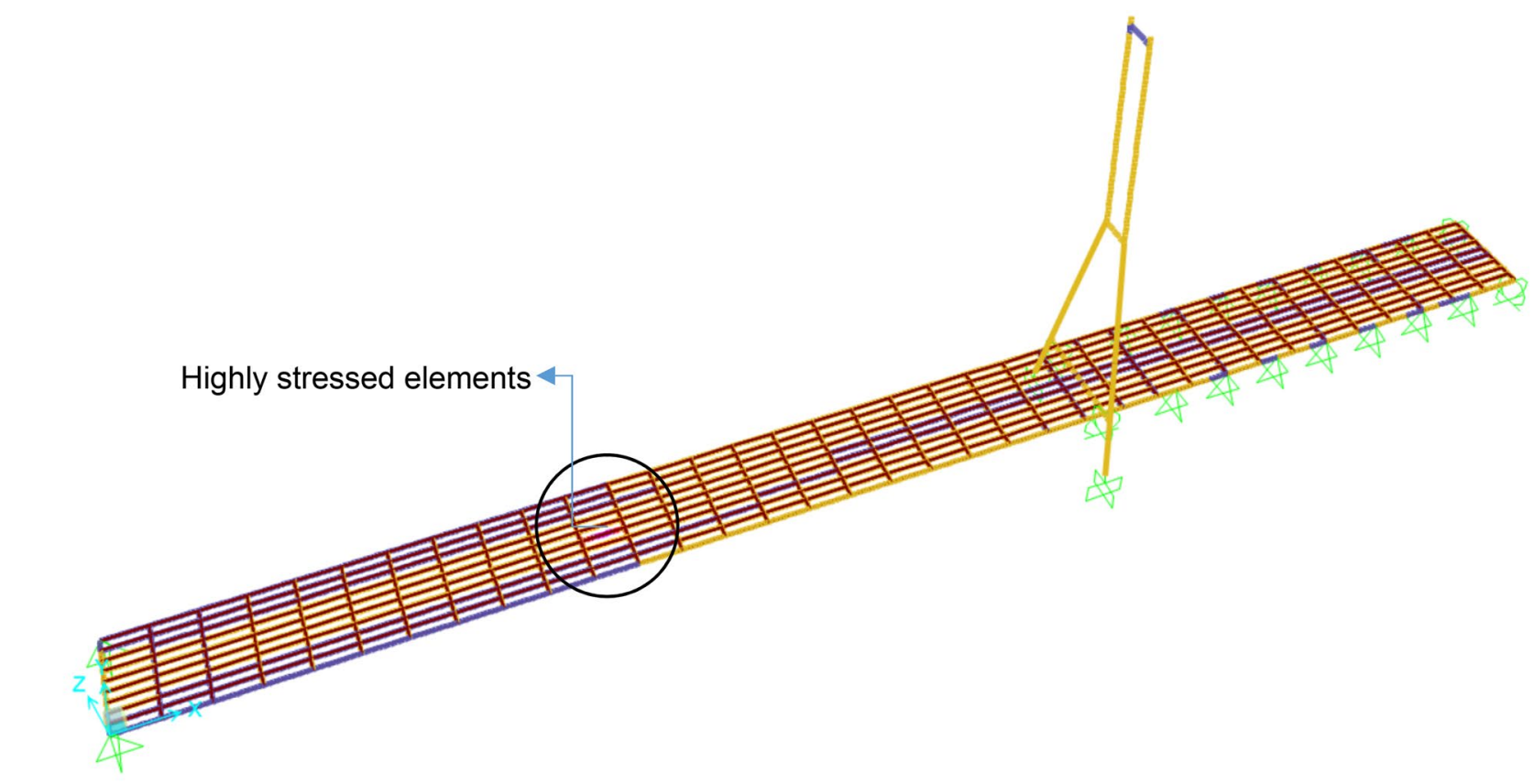

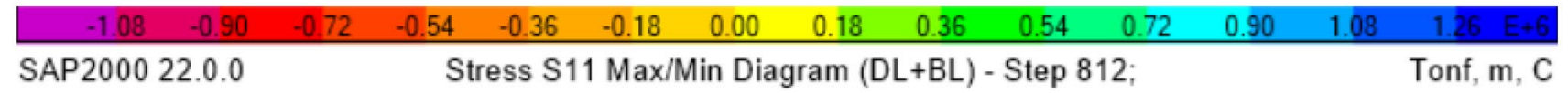

Fig. 29 Stress contours on the bridge due to blast loads in the middle of the main span

Fig. 30 Axial load in main span cables towards the tower

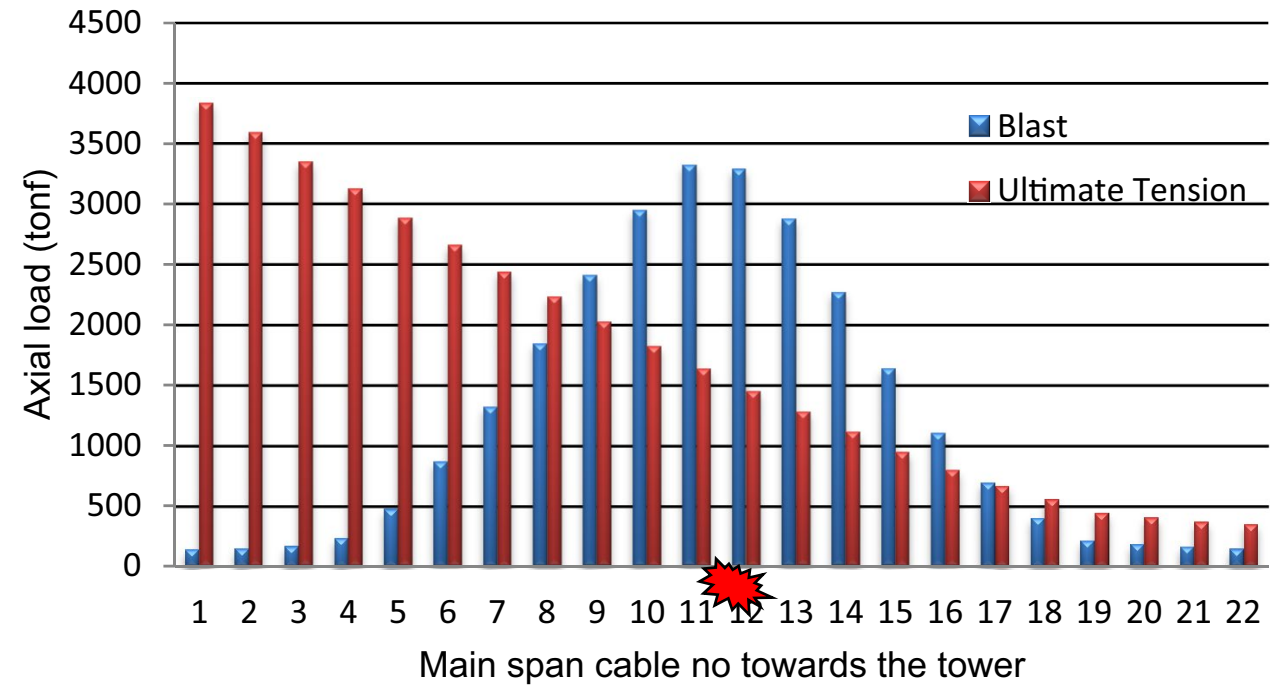

5 Observations and discussion

the bridge's localized failure caused the severe progressive collapse by failing more no of the girder elements (Fig. 44). It also pushed for the loss of a few more cables on both primary and back spans (Fig. 45) (Tables 7 and 8). Hence, blasting near the tower location is regarded as the worst scenario among all other blast locations.
(1) Model characteristics of the bridge (Charles River Crossing Cable-Stayed Bridge-Boston) were obtained with a fundamental time period of $5.48 \mathrm{~s}$. The fundamental mode shape showed the bridge's side bend, 
Fig. 31 Stress demand vs. capacity of girder elements

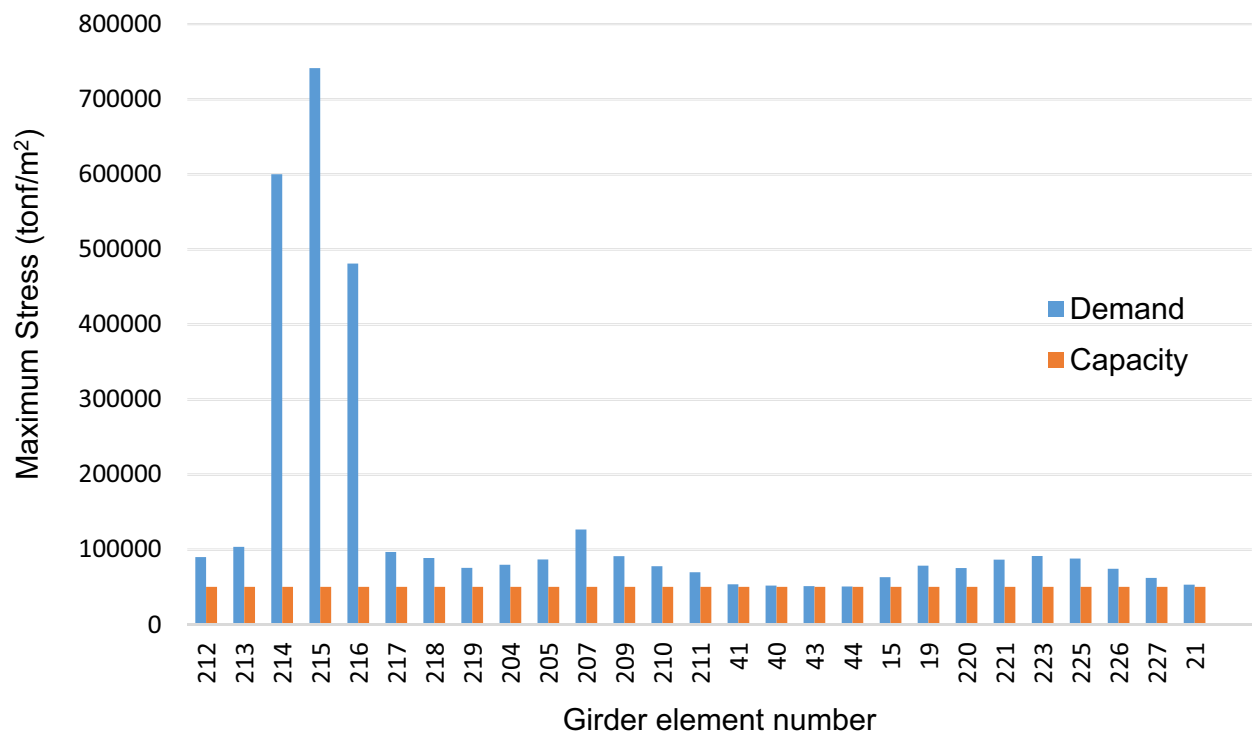

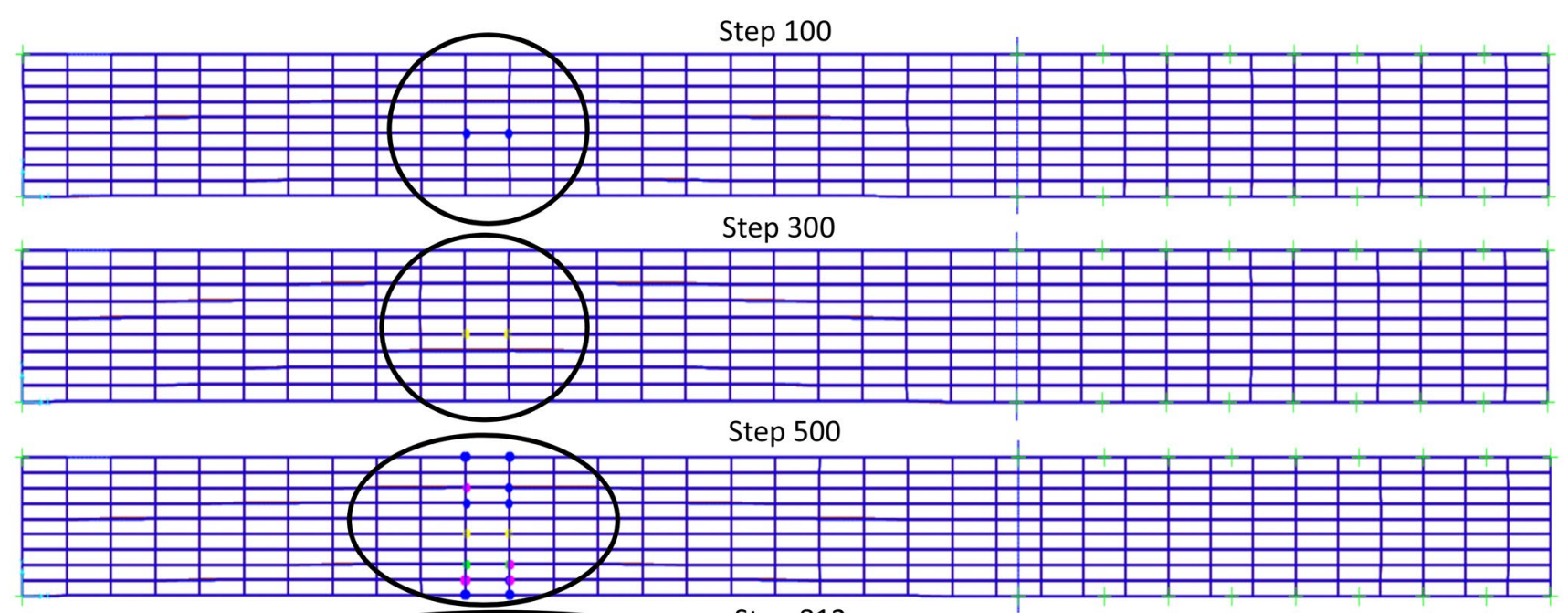

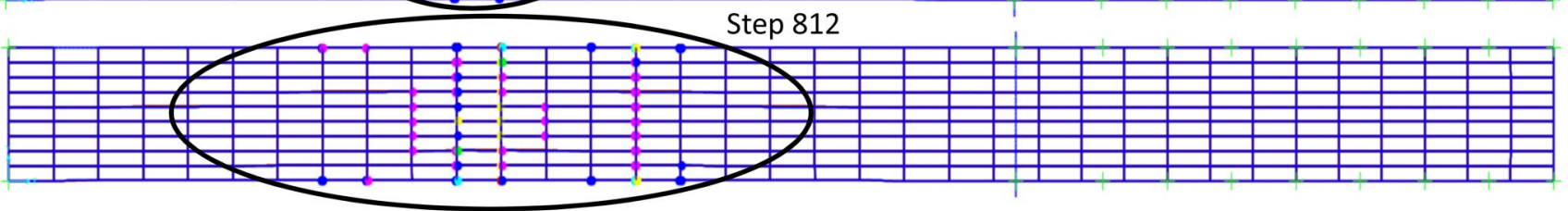

$\infty$

$\overline{0}$ $\bar{c}$

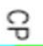

○

Fig. 32 Hinge formation due to blast load case-2

meaning by the lateral stiffness of the bridge was lesser than the vertical stiffness (Fig. 14).

(2) Blast load was applied on the bridge at three different locations, and observations were made as follows:

(a) Case-1: At the starting of the main span (i) The maximum joint displacement in the structural element was $3.6 \mathrm{~m}$ (Fig. 19).

(ii) No cable was found to be failed (Fig. 20).

(iii) Most of the girders (23) surrounding the blast location were failed (Figs. 21, 22).

(iv) The intensity of the bridge's localized collapse was further extended towards the 


\begin{tabular}{|c|c|c|c|c|c|c|c|c|c|c|c|c|c|c|c|}
\hline 39 & & & & & & 42 & & & & & 45 & 46 & 47 & & 48 \\
\hline 195 & & $\overline{\mathrm{X}}$ & $\frac{9}{8}$ & 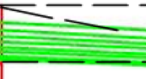 & 8 & $-\frac{\pi}{28}$ ) & 555531 & 5 & 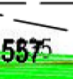 & 잉 & $556 \overline{243}$ : & $588^{251} \begin{array}{r}\$ \\
530^{m}\end{array}$ & $-529^{259}$ & $\begin{array}{l}1 \\
\infty \\
0 \\
0\end{array}$ & 267 \\
\hline 194 & क्ञ & 202 & న్ల & - & + & & & फ़ & 234 & फ़ & 242 ल & 250 ल & 258 & $\begin{array}{l}\text { () } \\
\text { ल) }\end{array}$ & 200 \\
\hline 193 & $\stackrel{\infty}{\sim}$ & 201 & N্ల & & 임 & के & & के & 233 & 总 & 241 @ & 249 ल & 257 & 包 & 265 \\
\hline 192 & $\stackrel{\mathrm{N}}{\mathrm{N}}$ & 200 & స్ల & 208 & & & 224 & 市 & 232 & 商 & $240 \stackrel{\varrho}{~}$ & 248 ल & 256 & $\begin{array}{l}\text { ఫे } \\
\text { ले }\end{array}$ & 264 \\
\hline 191 & $\stackrel{\text { w }}{\mathrm{N}}$ & 199 & ్ํ & & $\infty$ & & & 今े & 231 & $\begin{array}{l}\omega \\
6 \\
\text { ली } \\
\end{array}$ & $\begin{array}{l}0 \\
0 \\
0\end{array}$ & 247 ले & 255 & $\begin{array}{l}M \\
\infty \\
0 \\
0\end{array}$ & 263 \\
\hline 190 & $\stackrel{\text { ?ొ }}{\sim}$ & 198 & के & 206 & लै & & & $\begin{array}{l}0 \\
\text { ले }\end{array}$ & 230 & 员 & 238 हे & $246 \quad \stackrel{9}{2}$ & 254 & $\begin{array}{l}\mathrm{N} \\
\mathrm{p} \\
\mathrm{m}\end{array}$ & 262 \\
\hline 189 & $\stackrel{\bar{v}}{\mathrm{I}}$ & 197 & $\stackrel{\infty}{\infty}$ & & & & & ले & 229 & 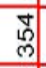 & \begin{tabular}{|lr} 
& \\
237 & @ \\
\end{tabular} & 245 ले & 253 & $\begin{array}{c}5 \\
\infty \\
m\end{array}$ & 261 \\
\hline 188 & $\stackrel{\text { ma }}{\sim}$ & 196 & 글 & & ص్m & ल্ল & 491 & 79 & 489 & Mํ. & $488 \quad 487 \approx$ & $486 \quad 485^{-}$ & 484 & of & 260 \\
\hline 军 & A & 2 & ले & $\geqslant-16$ & & & -20 & के & & 衿 & $-\frac{}{22}$ & 昂 & & -9 & 25 \\
\hline
\end{tabular}

(Dotted lines shows the

damaged beams and cables)

Fig. 33 Plan view of bridge deck after the localized collapse

Fig. 34 Stress demand vs. capacity of girder elementspost blast

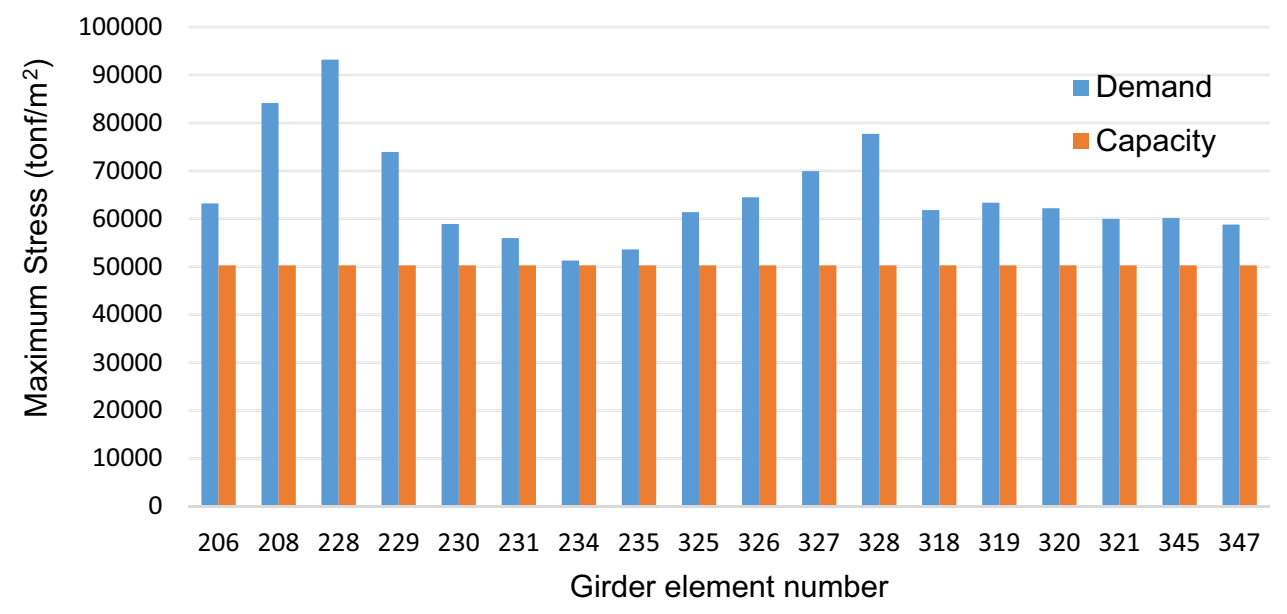

Fig. 35 Failure location of cables post-blast analysis

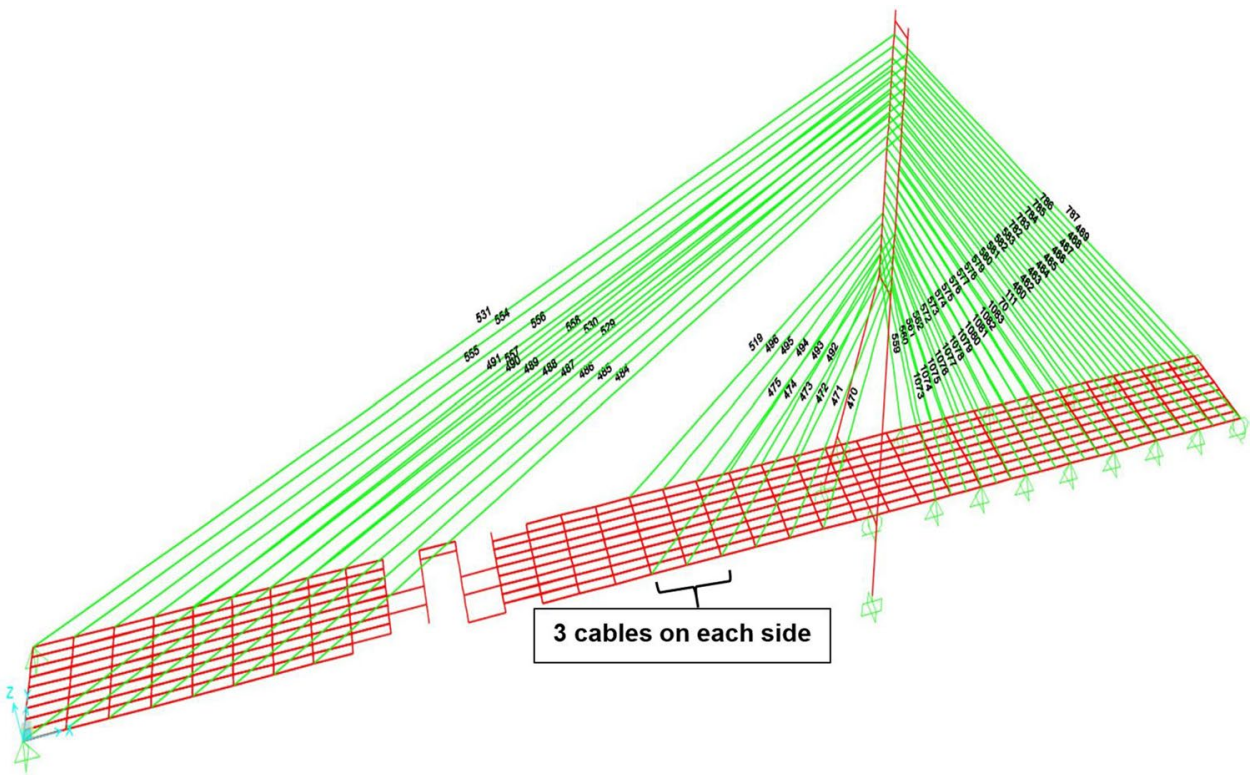

SN Applied Sciences a SPRINGER NATURE journal 
Table 6 Axial load demand vs. cable capacity-post blast

\begin{tabular}{lll}
\hline $\begin{array}{l}\text { Cable No (Towards the } \\
\text { Tower) }\end{array}$ & Axial load (tonf) & $\begin{array}{l}\text { Ultimate } \\
\text { strength } \\
\text { (tonf) }\end{array}$ \\
\hline 18 & 899 & 670 \\
19 & 665 & 558 \\
20 & 526 & 446 \\
\hline
\end{tabular}

tower side and caused the progressive collapse, as illustrated in (Figs. 24, 25).

(b) Case-2: At the middle of the main span

(i) The maximum joint displacement in the structural element was $7.2 \mathrm{~m}$ (Fig. 28).

(ii) Most of the girders (27) surrounding the blast location were failed (Figs. 29, 31) (iii) Nine cables (each on the front and rare side) were found to be failed near the blast location (Fig. 30).

(iv) The post-blast analysis of the bridge caused the failure of more girder elements (18 no.) (Fig. 34) and three more cables (each on both front and rare sides) (Fig. 35) (Table 5).

(v) Therefore, it is concluded that the blasting in the middle of the main span caused for more severe effect than the case-1.

\section{(c) Case-3: Near the tower}

(i) The maximum joint displacement in the structural element was $1.2 \mathrm{~m}$ (Fig. 38).

(ii) Twelve cables (each on the front and rare sides) were found to be failed near the blast location (Fig. 39).

(iii) Most of the girders (27) surrounding the blast location were failed (Figs. 40, 41).

(iv) At the end of the post-blast analysis, a few more girder elements ( $21 \mathrm{no}$ ) were failed (Fig. 44). It was

\begin{tabular}{|c|c|c|c|c|c|c|c|c|c|c|c|c|c|c|c|c|c|c|c|c|c|}
\hline 47 & & 48 & & 49 & & 50 & & 51 & & 52 & & 53 & & 505\% & 507 & 520 & 692 & 693 & 695 & 697 & 698 \\
\hline 259 & 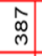 & 267 & $\begin{array}{l}0 \\
0 \\
\end{array}$ & 275 & 㝵 & 283 & $\frac{d}{\sigma}$ & 291 & 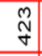 & 299 & $\begin{array}{c}\tilde{w} \\
\stackrel{p}{q} \\
\end{array}$ & 307 & $\begin{array}{c}- \\
\dot{z}\end{array}$ & $550 \stackrel{\mathrm{g}}{\mathrm{g}}$ & $584 \frac{\circ}{9}$ & 962 & & 963 总 & $965 \quad \overline{0}$ & 967 ్ֻల్ & 969 \\
\hline 258 & 惫 & 266 & 怘 & 274 & $\begin{array}{l}\text { ơ } \\
\dot{q}\end{array}$ & 282 & $\frac{\alpha}{\sigma}$ & 290 & 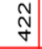 & 298 & gे & 306 & g & $540 \hat{\text { Na }}$ & $5488^{\circ}$ & 939 & & 940 总 & 942 & 944 & 946 \\
\hline 257 & $\begin{array}{c}n \\
\infty \\
m\end{array}$ & 265 & 离 & 273 & ô & 281 & $\frac{d}{N}$ & 289 & $\begin{array}{c}\bar{N} \\
\text { y }\end{array}$ & 297 & 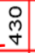 & 305 & ơ & $542 \overline{2}$ & $5444_{f}^{\infty}$ & 916 & & 917 怘 & $919 \frac{m}{6}$ & 921 ஜ & 923 \\
\hline 256 & 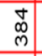 & 264 & 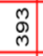 & 272 & $\begin{array}{l}N \\
\alpha \\
\sigma \\
\end{array}$ & 280 & $\begin{array}{l}+ \\
\end{array}$ & 288 & \begin{tabular}{l}
\multirow{2}{*}{} \\
y \\
\end{tabular} & 296 & 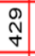 & 304 & 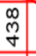 & $5388_{\ulcorner}^{\circ}$ & $540 \frac{q}{q}$ & 893 & & $894 \stackrel{\circ}{8}$ & $896 \quad \frac{5}{6}$ & 898 ह్ల & 900 \\
\hline 255 & 离 & 263 & స్ల్లి & 271 & ó & 279 & $\stackrel{0}{\square}$ & 287 & $\frac{a}{\sigma}$ & 299 & 㐫 & $w$ & 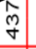 & $5340^{\circ}$ & $5366_{\frac{0}{7}}^{\circ}$ & 870 & & 871 & $873 \quad$ & 875 & 877 \\
\hline 254 & 㐫 & 262 & $\overline{\mathscr{m}}$ & 270 & ঃ & 278 & $\begin{array}{l}q \\
q \\
q\end{array}$ & 286 & $\begin{array}{l}\infty \\
\sigma \\
\sigma\end{array}$ & 294 & $\begin{array}{c}\hat{N} \\
\hat{y}\end{array}$ & 362 & $\begin{array}{l}0 \\
\substack{0 \\
y \\
y}\end{array}$ & $518 \mathrm{~m}$ & $5322^{20}$ & 847 & & 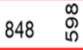 & $850 \stackrel{6}{6}$ & 852 ర్ల & 854 \\
\hline 253 & 㐫 & 261 & 吕 & 269 & $\begin{array}{l}8 \\
0 \\
m\end{array}$ & 277 & $\begin{array}{l}\infty \\
o \\
+\end{array}$ & 285 & $\begin{array}{l}q \\
q\end{array}$ & 293 & 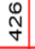 & 301 & 怨 & $513^{\infty}$ & $515 \frac{q}{q}$ & 824 & & $825 \stackrel{\circ}{8}$ & 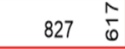 & 829 ్ֶల & 831 \\
\hline 252 & $\begin{array}{c}0 \\
\infty \\
m \\
m\end{array}$ & 260 & $\begin{array}{c}2 \\
\infty \\
m \\
m\end{array}$ & 268 & $\begin{array}{l}0 \\
0 \\
0 \\
\end{array}$ & 276 & ô & 284 & $\begin{array}{l}0 \\
\frac{1}{q}\end{array}$ & 292 & đู & 300 & 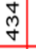 & $50 \%$ & $511 \frac{\pi}{q}$ & 790 & & $802:$ & $804 \stackrel{\infty}{6}$ & $806 \quad \begin{array}{l}0 \\
0\end{array}$ & 808 \\
\hline 24 & 命 & 25 & 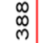 & 26 & ఏ్లి & 27 & 旁 & 28 & $\stackrel{n}{\sigma}$ & 29 & ปู & 30 & 誉 & 501\% & $503 \frac{\tilde{y}}{\tilde{y}}$ & 461 & 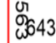 & $644 \overline{0}$ & $64 \hat{\sigma}$ & $657_{00}^{\circ}$ & 658 \\
\hline
\end{tabular}

Fig. 36 Blast location on the main span near the tower

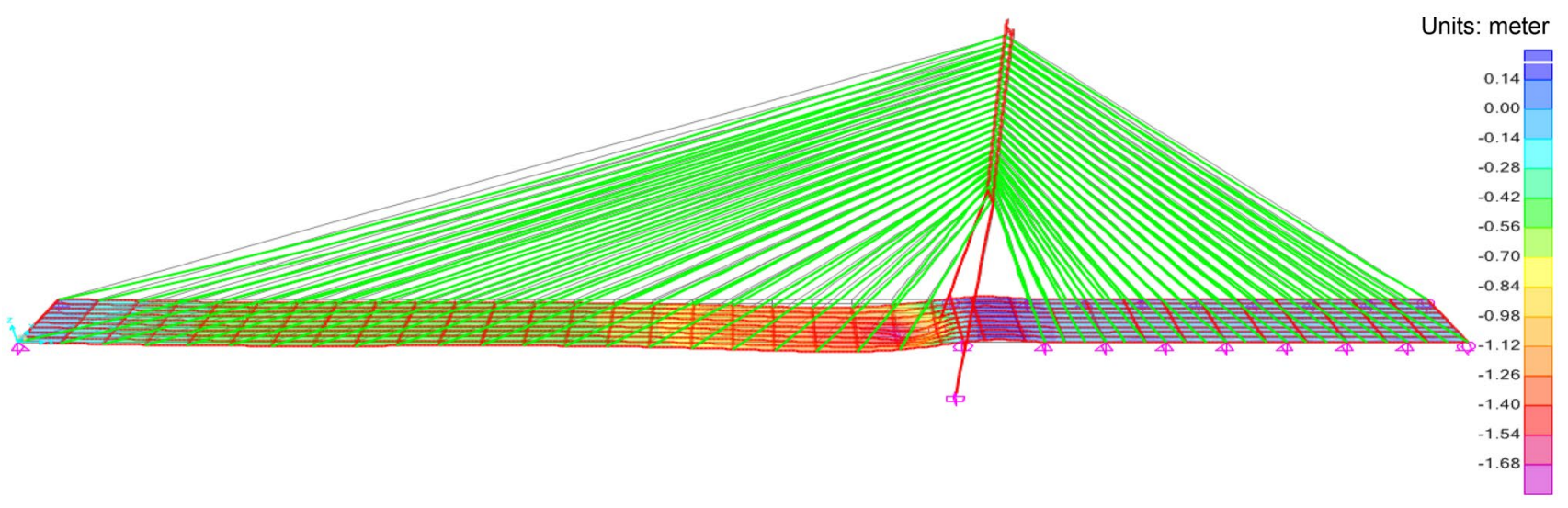

Fig. 37 Displacement contour 
Fig. 38 Joint displacement in the main span towards the tower

Fig. 39 Axial load in the main span cables near the tower

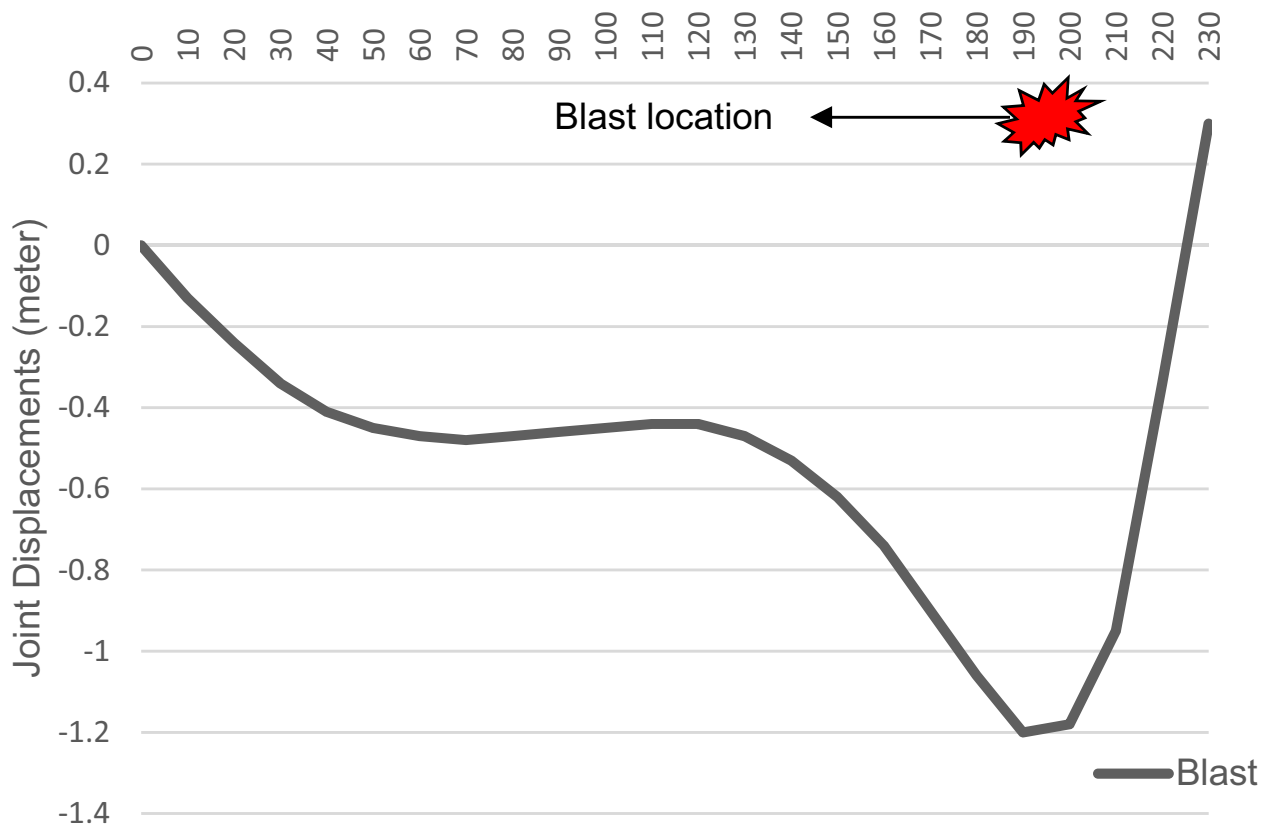

Main span towards the tower

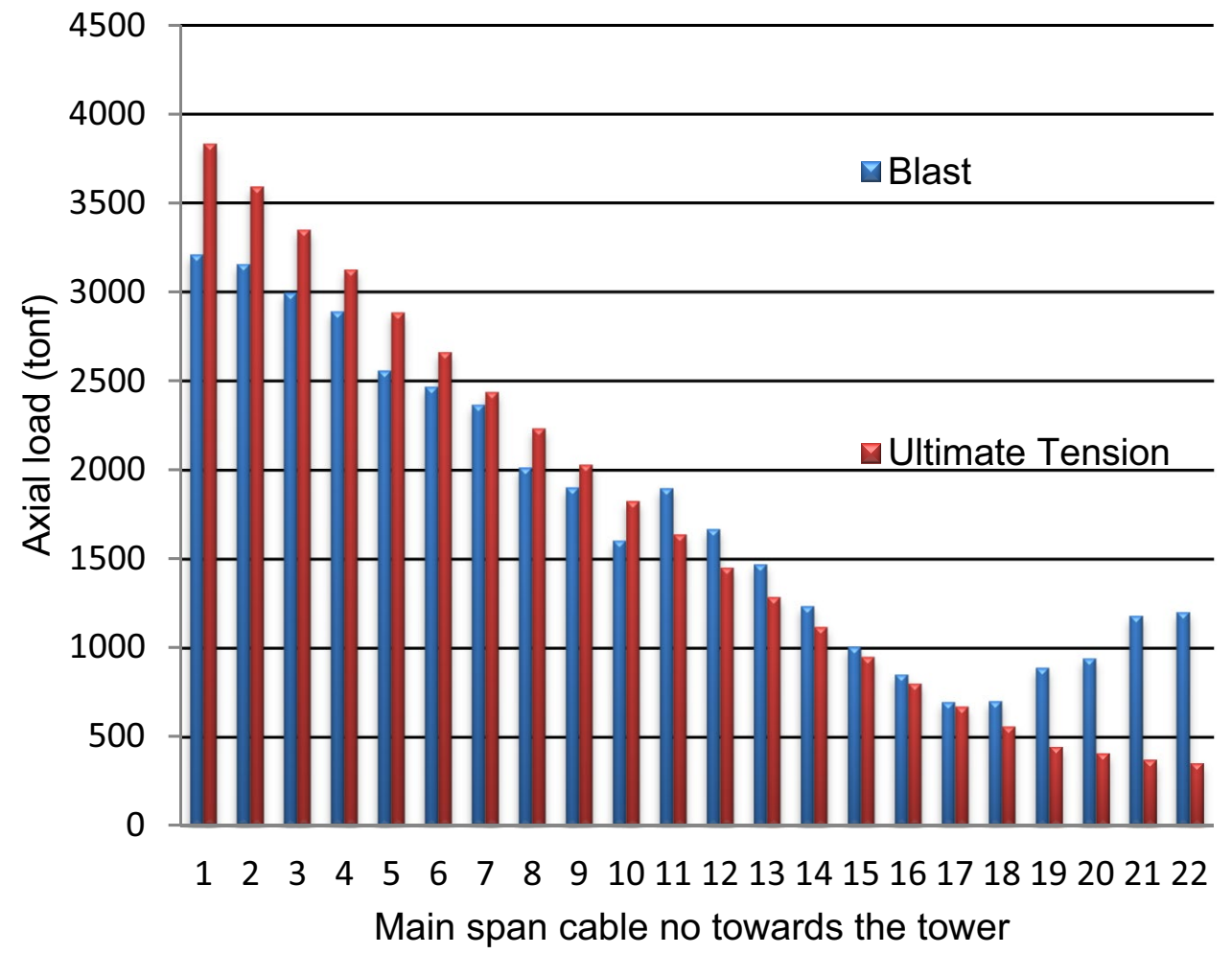

also observed that a further failure of cables (five on the main span and three on the back span) during the post-blast analysis (Fig. 45) (Tables 6, 7).

(v) Therefore, blasting near the tower caused more severe damage to the bridge than in case 1 and 2 .

\section{Conclusions}

Charles River Crossing Cable-Stayed Bridge-Boston was used as a case study to understand its robustness and progressive collapse resistance against the blast loads. 


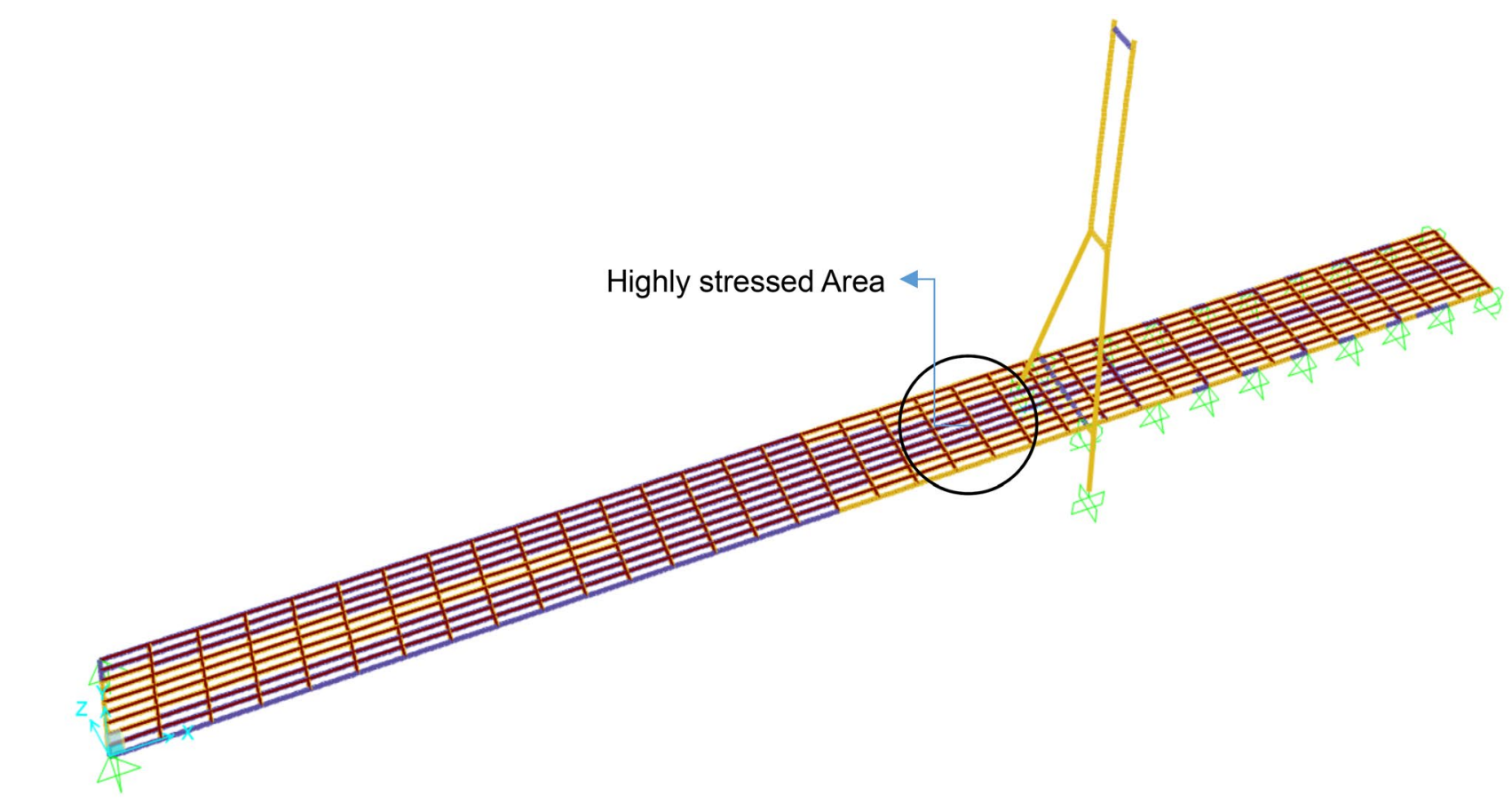

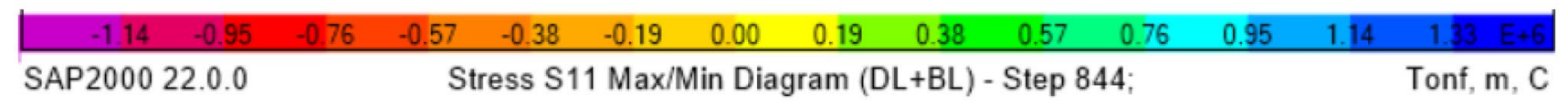

Fig. 40 Stress contours on the bridge due to blast loads in the center of the main span-near the tower

Fig. 41 Stress demand vs. capacity of girder elements

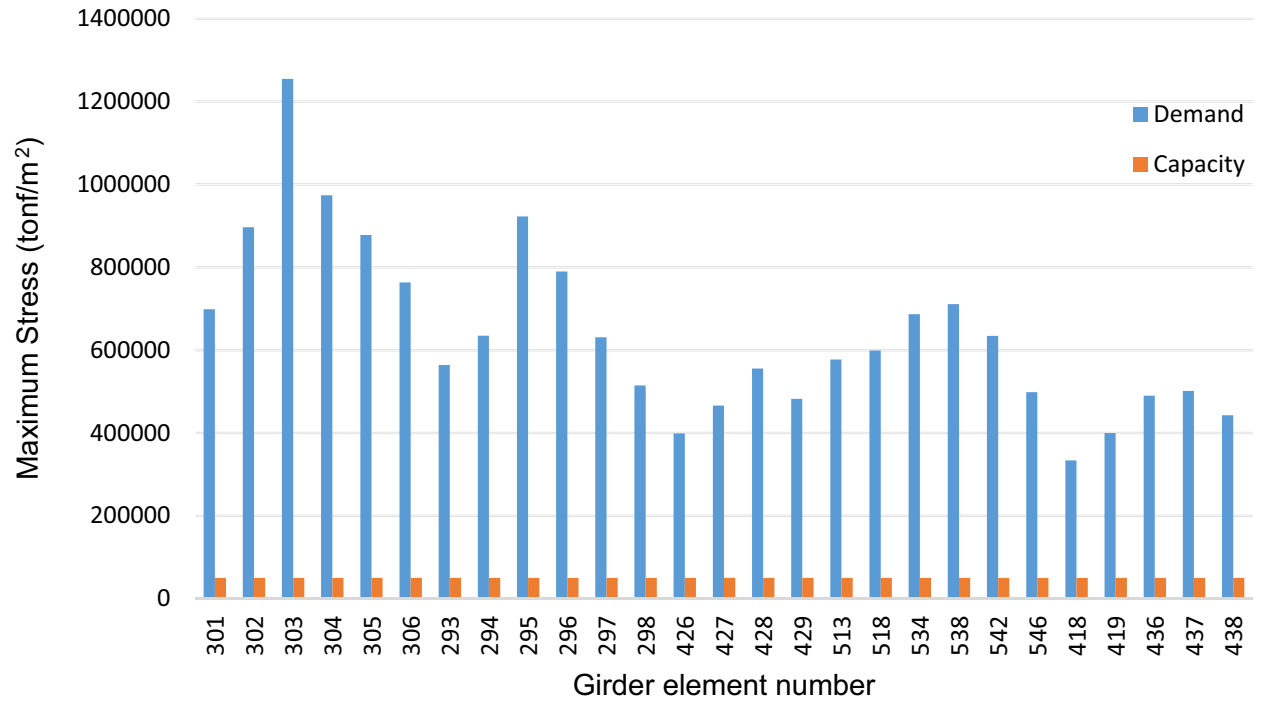

A modal analysis was performed to observe the characteristics of the cable-stayed bridge. The fundamental mode shape suggested that the lateral stiffness of the bridge was lesser than its vertical stiffness. Basic guidelines were provided to avoid the difficulties of simulating the blast loads. The blast was applied at three different locations on the bridge, and corresponding responses were noted down and analyzed. Plastic hinges were assigned in the structural elements around the blast 

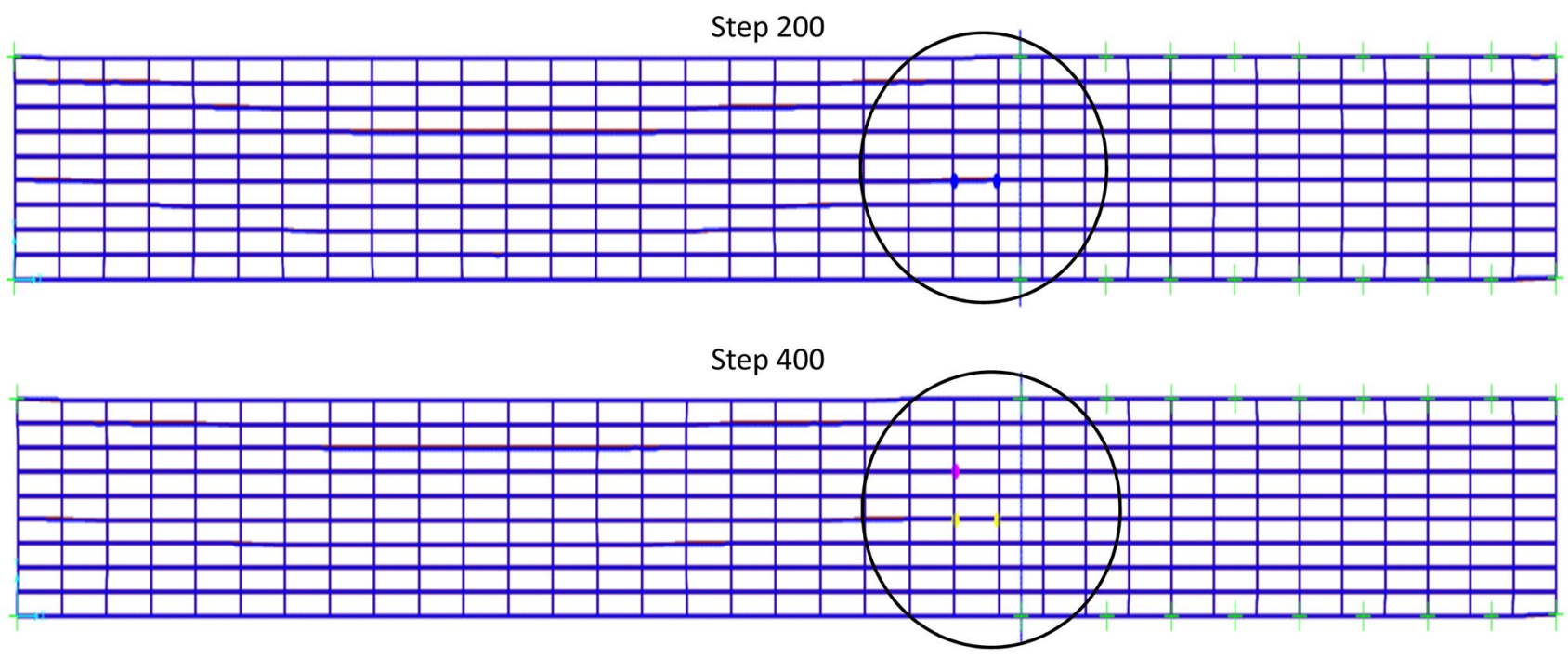

Step 600
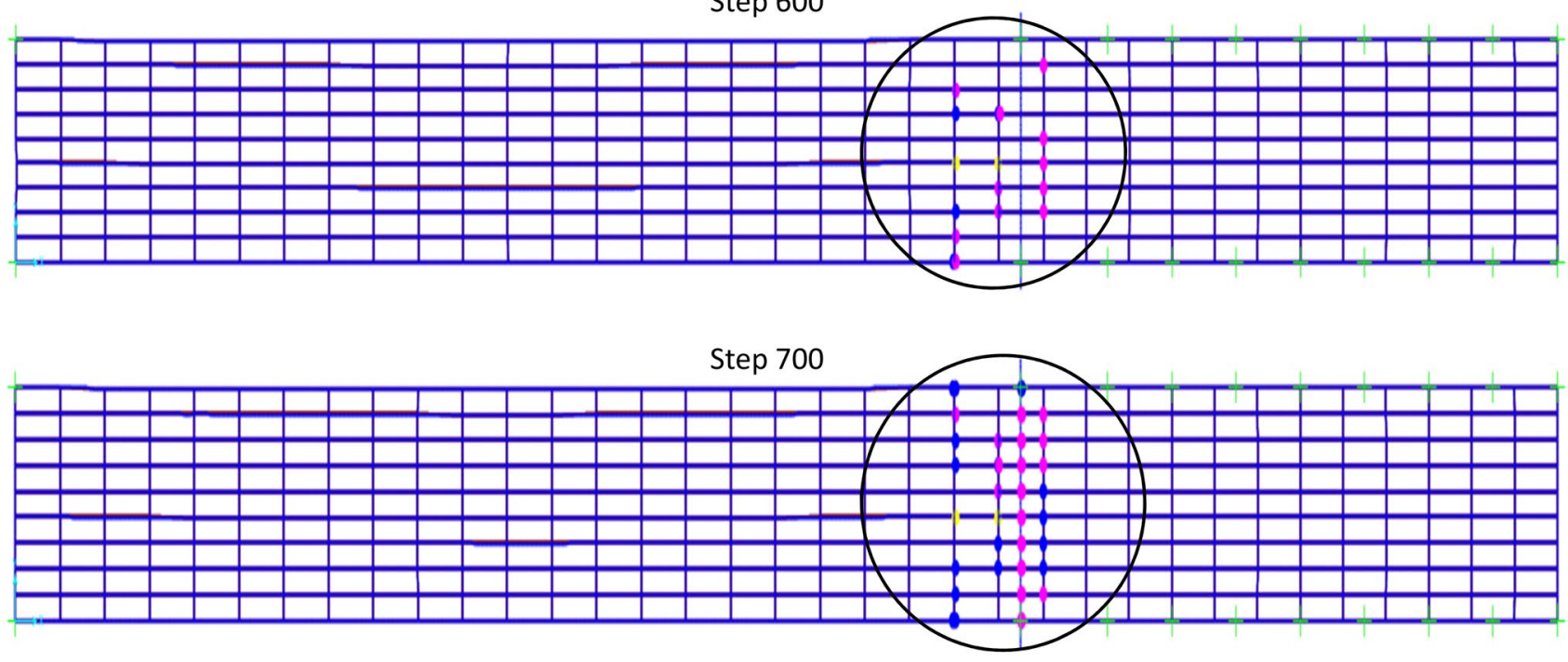

Step 844

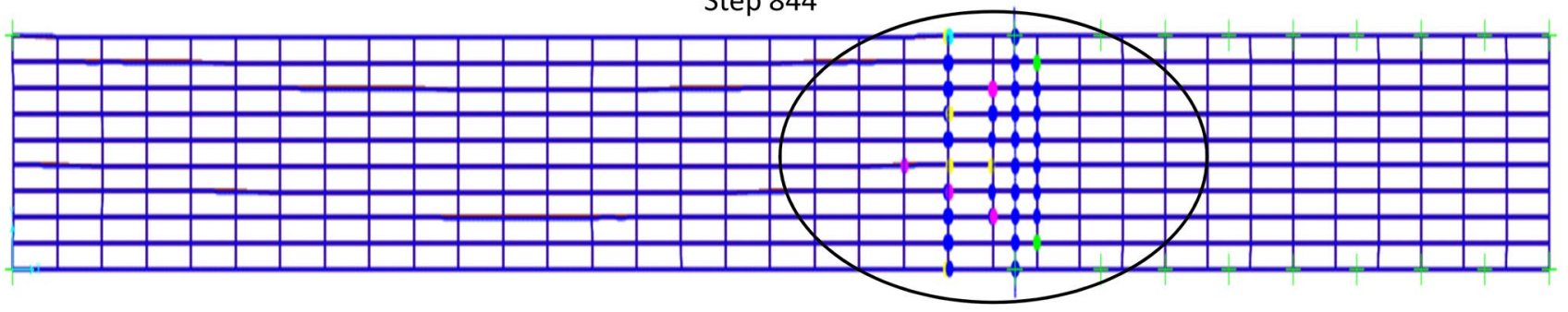

$\infty$

$\overline{0}$

is

8

○ m

Fig. 42 Hinge formation due to blast load case-2 


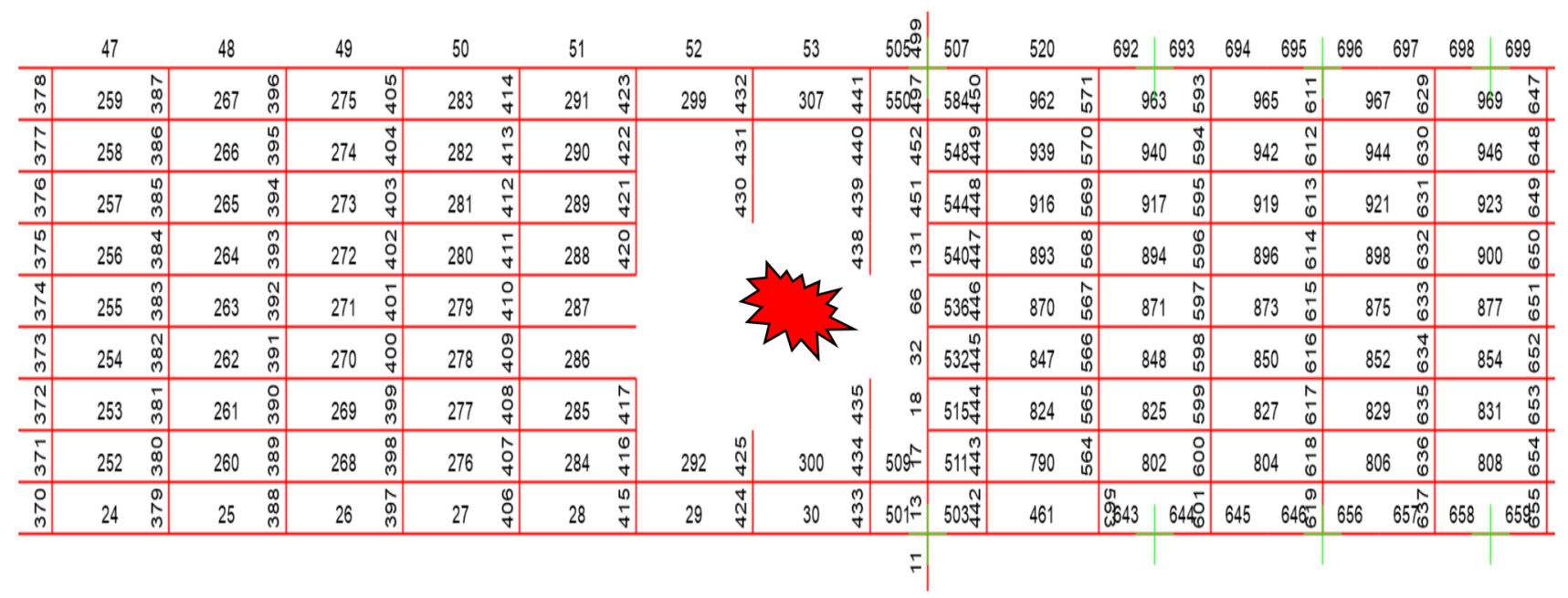

Fig. 43 Plan view of bridge deck after the localized collapse

Fig. 44 Stress demand vs. capacity of girder elementspost blast
120000

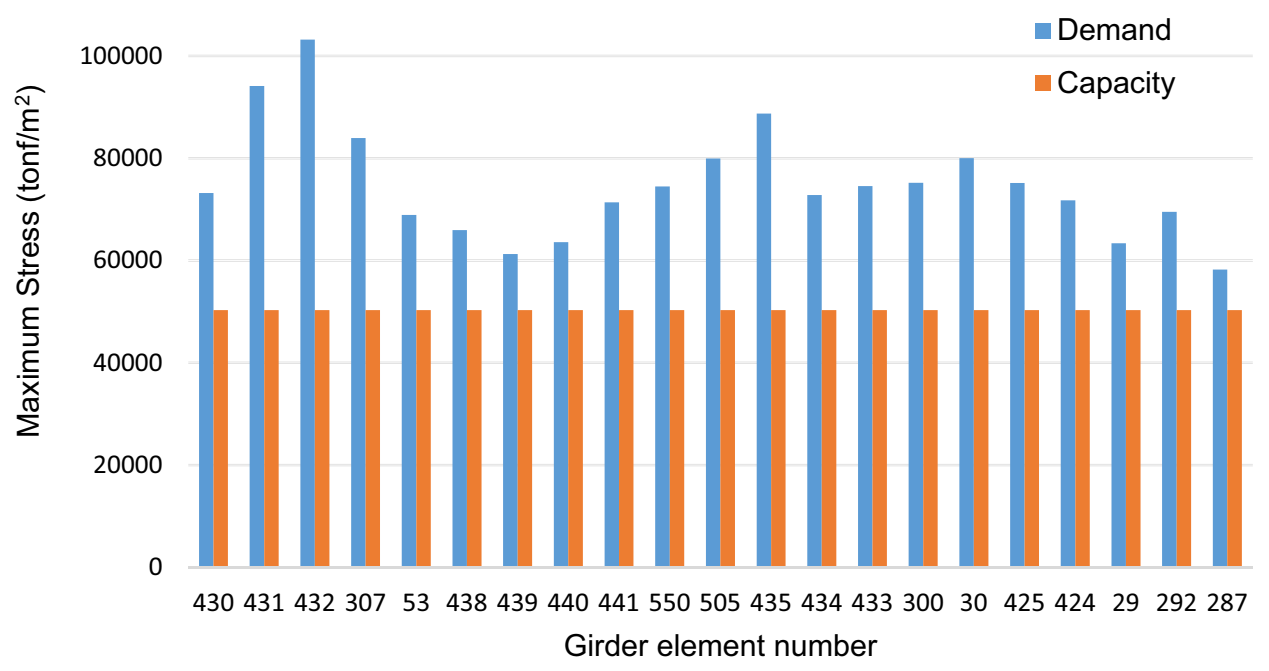

locations, and post-yield behavior was studied. The key conclusions of the study are summarized below.

1. In general, it is difficult to simulate the blast effects and predict the response of the cable-stayed bridges to blast loads. Hence, an effortless way of applying the blast load had been developed in this study. 3-dimensional modeling of the cable-stayed bridge was carried out in SAP 2000, and its response to blast loads had been observed.

2. The cable-stayed bridge's response to blast load was estimated by computing the maximum stresses in girder members and cables, which cause localized failure and, in turn, lead to the bridge's progressive collapse. Result concluded that the cable-stayed bridge was too weak to sustain the blast loads near the tower location. Moreover, the bridge deck's localized failure near the tower location causes the entire bridge's progressive collapse. Thus, these results clearly show the need for an effective multi-hazard design of cable-stayed bridges, and focus should be given on the bridge girder and cable elements near the tower locations. The considered cable-stayed bridge has exhibited different mechanisms in all the blast load cases. Mechanisms such as spalling of tower and postyielding of longitudinal and transverse beams will occur at any location and under any intensity of blast load. Hence, these mechanisms should be specially addressed in the multi-hazard design. 


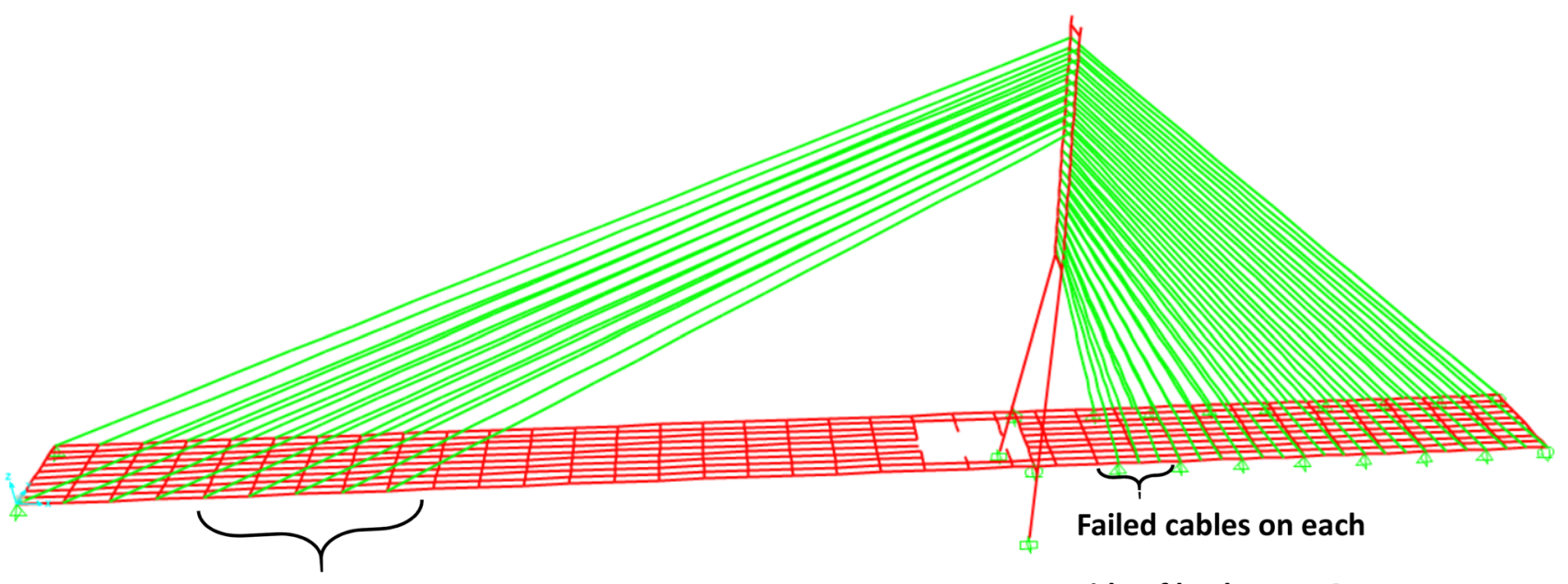

Failed cables on each side of main span: 5

side of back span: 3

Fig. 45 Progressive collapse of cables and girder after localized collapse

Table 7 Axial load in cables demand vs. capacity (main span)-post blast

\begin{tabular}{lll}
\hline $\begin{array}{l}\text { Cable No (Towards the } \\
\text { tower) }\end{array}$ & Axial load (tonf) & $\begin{array}{l}\text { Ultimate } \\
\text { strength } \\
\text { (tonf) }\end{array}$ \\
\hline 6 & 2933 & 2659.8 \\
7 & 2696 & 2436.6 \\
8 & 2421 & 2232 \\
9 & 2169 & 2027.4 \\
10 & 2025 & 1822.8 \\
\hline
\end{tabular}

Table 8 Axial load in cables demand vs. capacity (back span)-post blast

\begin{tabular}{lll}
\hline $\begin{array}{l}\text { Cable No (Away from the } \\
\text { tower) }\end{array}$ & Axial load (tonf) & $\begin{array}{l}\text { Ultimate } \\
\text { strength } \\
\text { (tonf) }\end{array}$ \\
\hline 1 & 1495 & 353.4 \\
2 & 1001 & 372 \\
3 & 820 & 409.2 \\
\hline
\end{tabular}

3. The study further focused on progressive failure mechanisms through the pre-defined plastic hinges near the blast locations. Out of all the considered blast scenarios on the bridge deck, severe damage mechanisms were observed through the hinge results near the tower location. The result showed that most of the bridge girder and cable elements near the tower location were in the collapse prevention stage, and hence progressive failure was evident. Therefore, this case study clearly shows the vulnerability of cable-stayed bridges to blast loads near the tower locations and the importance of blast resistant design in bridges.

4. Instead of using continuum-based finite element simulations and actual modeling of blast loads, in this paper, beam elements were used for modeling the bridge components, and equivalent quasi-static loads were applied on the bridge. This study can be effectively used to supplement the finite element simulations and save computational time and resources. This case study helps the designer better understand the robustness of cable-stayed bridges under blast loads and the importance of its characteristics in resisting the progressive collapse. This study contributes to the knowledge in bridge engineering by concluding the volume of bridge design to high impact and explosive loads.

\section{Compliance with ethical standards}

Conflict of interest The authors declare that they have no conflict of interest.

Open Access This article is licensed under a Creative Commons Attribution 4.0 International License, which permits use, sharing, adaptation, distribution and reproduction in any medium or format, as long as you give appropriate credit to the original author(s) and the source, provide a link to the Creative Commons licence, and indicate if changes were made. The images or other third party material in this article are included in the article's Creative Commons licence, unless indicated otherwise in a credit line to the material. If material is not included in the article's Creative Commons licence and your intended use is not permitted by statutory regulation or exceeds the permitted use, you will need to obtain permission directly from the copyright 
holder. To view a copy of this licence, visit http://creativecommons .org/licenses/by/4.0/.

\section{References}

1. Draganic H, Sigmund V (2012) Blast loading on structures. Tech Gaz 19(3):643-652

2. Winget DG et al (2005) Analysis and design of critical bridges subjected to blast loads. J Struct Eng ASCE 31(8):1243-1255. https://doi.org/10.1061/(ASCE)0733-9445(2005)131:8(1243)

3. Pan Y, Ventura CE, Cheung MMS (2017) Performance of highway bridges subjected to blast loads. Eng Struct 151:788801. https://doi.org/10.1016/j.engstruct.2017.08.028 (ISSN 0141-0296)

4. Cofer* WF, Matthews DS, McLean DI (2010) Effects of blast loading on prestressed girder bridges. Shock and Vibration 19:1-181

5. Farahmand-Tabar S, Barghian M (2020) Seismic assessment of a cable-stayed arch bridge under three-component orthotropic earthquake excitation. Adv Struct Eng. https://doi. org/10.1177/1369433220948756

6. Farahmand-Tabar S, Barghian M, Vahabzadeh M (2019) Investigation of the progressive collapse in the suspension bridge under explosion. Int J Steel Struct 19:2039. https://doi.org/10.1007/ s13296-019-00263

7. Farahmand-Tabar S, Barghian M (2020) Response control of cable-stayed arch bridge using modified hanger system. J Vib Control. https://doi.org/10.1177/1077546320921635

8. Tetougueni CD, Zampieri P (2019) Structural response of cablestayed bridge subjected to blast load. Procedia Struct Integr 18:765-774. https://doi.org/10.1016/j.prostr.2019.08.225 (ISSN 2452-3216)

9. Son Jin, Lee Ho-Jung (2010) Performance of cable-stayed bridge pylons subjected to blast loading. Eng Struct 33(4):11331148. https://doi.org/10.1016/j.engstruct.2010.12.031 (ISSN 0141-0296)

10. Shukla PJ, Modhera CD (2015) Dynamic response of cablestayed bridge pylon subjected to blast loading. In: Matsagar V (ed) Advances in structural engineering. Springer, New Delhi

11. TM5-1300 (1979) Structures to resist the effects of accidental explosions, U.S. Department of the Army, Navy and Air Force Tecnical Manual, Washington, DC, USA

12. Hao H, Tang EKC (2010) Numerical simulation of a cable-stayed bridge response to blast loads, part II: damage prediction and FRP strengthening. Eng Struct 32:3193-3205. https://doi. org/10.1016/j.engstruct.2010.06.006

13. Hashemi SK, Bradford MA, Valipour HR (2016) Dynamic response of cable-stayed bridge under blast load. Eng Struct 127:719-736
14. Domaneschi M et al (2020) Collapse analysis of the Polcevera Viaduct by the applied element method. Eng Struct 214:110659. https://doi.org/10.1016/j.engstruct.2020.110659

15. Domaneschi M, Cimellaro GP, Scutiero G (2019) Disproportionate collapse of a cable-stayed bridge. Bridge Eng ICE 172(1):1326. https://doi.org/10.1680/jbren.18.00031

16. Gholipour G, Zhang C, Mousavi AA (2019) Nonlinear numerical analysis and progressive damage assessment of a cable-stayed bridge pier subjected to ship collision. Mar Struct 69:102662. https://doi.org/10.1016/j.marstruc.2019.102662

17. Davalos, E (2000) Structural behavior of cable-stayed bridges, Ph.D. thesis, Massachusetts Institute of Technology

18. SAP (2000), Structural analysis program. Computers and structures

19. Suthar, KN (2007), The effect of dead, live and blast loads on a suspension bridge. Master of Science thesis, department of civil and environmental engineering, college park (USA): University of Maryland

20. FEMA-356 (2000), Prestandard and Commentary for the Seismic Rehabilitation of Buildings. Federal Emergency Management Agency, 20191 (703): 295-6000

21. ARA (1979), Applied research associates, United States of America

22. ATBlast (1980), Software for calculating blast load parameters, Applied Research Associates: United States of America

23. The Blue Ribbon Panel on Bridge and Tunnel Security (2003) Recommendations for bridge and tunnel security. Federal Highway Administration, Washington, DC (FHWA-RD-03-021)

24. Islam AKMA, Yazdani N (2008) Performance of AASHTO girder bridges under blast loading. Eng Struct 30:1922-1937. https:// doi.org/10.1016/j.engstruct.2007.12.014

25. Wu CQ, Hao H (2005) Modelling of simultaneous ground shock and air blast pressure on nearby structures from surface explosion. Int J Impact Eng 31:699-717. https://doi.org/10.1016/j. ijimpeng.2004.03.002

26. Remennikov, AM (2004), Evaluation of blast loads on buildings in urban environment, Proceedings of the 8th international conference on structures under shock and impact, Greece

27. Tang KC, Hao H (2010) Numerical simulation of cable-stayed bridge response to blast loads, part 1: model development and response calculation. Eng Struct 32(10):3180-3192. https://doi. org/10.1016/j.engstruct.2010.06.007

Publisher's Note Springer Nature remains neutral with regard to jurisdictional claims in published maps and institutional affiliations. 